\title{
Creep crack growth in power plant materials
}

\author{
PARMEET S GROVER and ASHOK SAXENA \\ School of Materials Science \& Engineering, Georgia Institute of Technology, \\ Atlanta, GA 30332-0245, USA
}

\begin{abstract}
Economic considerations have made it desirable to extend the 30 to 40 year operating life of power plants by another 10 to 20 years. Crack growth at elevated temperatures is an important consideration in estimating the remaining life, determining operating conditions and deciding inspection criteria and intervals for power plant materials. This paper presents an overview of high-temperature crack growth phenomenon in such materials. The focus is on various techniques used for characterizing creep crack growth (CCG) and creep-fatigue crack growth (CFCG) in hightemperature materials. The collection of data, their analysis and the interpretation of results is discussed in detail, especially for CFCG laboratory testing. The discussion is primarily focussed on creep-ductile materials such as those used in power plant applications. Special considerations for elevated temperature crack growth in weldments are also presented. Finally. the application of these concepts to the life prediction of power plant components is also discussed.
\end{abstract}

Keywords. Creep crack growth; power plant applications; creep-fatigue crack growth; high temperature crack growth; life of power plants.

\section{Introduction}

A significant number of power plants all over the world have been in operation for durations close to their design lives of 30 to 40 years. Due to economic considerations it is desirable to extend their operating life by another 10 to 20 years. According to economic studies, the cost of life extension of a typical power plant is only $20 \%$ to $30 \%$ of the cost of building a new plant whereas the benefits are much higher (Dooley \& Viswanathan 1987). In order to ensure that power plant components are retired for cause rather than on the basis of their 'design life', remaining-life-assessment must be made. Crack growth at elevated temperatures becomes an important consideration in the estimation of remaining life, in the determination of operating conditions and in deciding inspection criterion and intervals. Fracture mechanics approaches that have been developed over the past few decades have proven useful in providing a rigorous framework for accomplishing these goals.

In the next few sections, an overview of the materials commonly used in fossil power plant components, the service conditions they are exposed to and the types of failures 
that are commonly encountered during service is provided. This information is used as the basis to provide motivation for the use of remaining crack growth life assessment technology for life prediction and deciding safe inspection intervals for components in these power plants. The relevance of high temperature crack growth and fracture mechanics approaches in this context has been highlighted.

\subsection{Materials used in power plant components}

Power plant components are made of a variety of materials which are capable of withstanding a wide range of operating conditions in the plant, depending upon the local conditions of pressure, temperature and chemical environment (Viswanathan 1989). Low-alloy ferritic steels containing carbon, molybdenum and/or vanadium constitute the bulk of the material used in steam power plants (Viswanathan 1989). High-alloyed tempered martensitic steels containing $\sim 12 \% \mathrm{Cr}$ along with $\mathrm{Ni}$ and $\mathrm{Co}$ based superalloys are the other widely used materials. Table 1.1 in Altekan (1980) gives the properties required for various components in steam power plants and the materials used for their construction.

The materials mentioned above are subjected to demanding pressure and temperature conditions which are summarized by Jaffee (1979) for a steam power plant. These demanding conditions lead to the degradation of these materials and consequently to the partial or complete failure of the component.

\subsection{Definitions of failure of components}

While catastrophic fracture or rupture is the most evident form of failure, table 1 (Viswanathan \& Dooley 1986) shows the various failure criteria and definitions used by the industry to retire a component before such failures occur. Failure of a component

Table 1. Failure criteria and definitions of component life.

History-based criteria

30 to 40 years have elapsed

Statistics of prior failures indicate impending failure

Frequency of repair renders continued operation uneconomical

Calculations indicate life exhaustion

Performance-based criteria

Severe loss of efficiency indicating component degradation

Large crack manifested by leakage, severe vibration, or other malfunction

Catastrophic burst

Inspection-based criteria

Dimensional changes have occurred, leading to distortions and changes in clearances

Inspection shows microscopic damage

Inspection shows crack initiation

Inspection shows large crack approaching critical size

Criteria based on destructive evaluation

Metallographic or mechanical testing indicates life exhaustion

From Viswanathan \& Dooley (1986) 
may generally be defined as the inability to perform its intended function reliably, economically and/or safely (Viswanathan 1989).

1.2a Crack growth at elevated temperatures: A number of crack growth mechanisms operate at the elevated temperatures to which power plant components are subjected. These include creep, creep-fatigue, oxidation, stress corrosion cracking, corrosionfatigue and thermal-fatigue. Often more than one of these operate simultaneously and probably have synergistic effects on the rate of crack growth and, consequently, on the material degradation. Hence, the study of elevated temperature crack growth is vital for understanding failure of power plant components.

1.2b Retirement of components from service: Economics rather than technical need has often formed the basis for decisions to retire components from service in the past because an investigation into the cost to benefit ratio of keeping the component in service may prove expensive. This is due to the high cost of carrying out remaining-life calculations based on the operating history, regular inspections and material testing. Further, if the decision arrived at after expensive analysis is not favorable, the economic penalties can be severe. This requires that life prediction methods be accurate and must also be inexpensive to perform.

\subsection{Motivation for life prediction}

Due to the high expenses associated with a forced plant outage, the conservative practice has been to replace certain components, or those which have a history of failure, after a fixed interval of time regardless of their actual condition. However, with the recent developments in areas such as fracture mechanics, materials testing and NDE techniques, confidence has increased in the application of these concepts for life prediction and consequently extending component life beyond their 'design life' and up to their 'actual life'. Some other factors which have contributed to the desire of extending plant life and consequently encouraging the use of remaining-life-assessment technology are (Viswanathan 1989):

(a) the escalating cost of new construction and diminishing capital resources;

(b) extended lead times in plant construction;

(c) uncertainties in projected demand growth rates;

(d) limited availability of suitable sites for new construction;

(e) increasingly stringent environmental, safety and other regulations.

A very important use of life-prediction procedures, besides extending plant life, is the determination of safe intervals for inspection, repair and maintenance. Thus, in order to carry out these steps of remaining-life-assessment technology, study of high-temperature crack growth in power plant materials becomes very important.

\subsection{Objectives of this paper}

In keeping with the current needs of the power generation industry to extend the operating life of existing power plants, a study of high-temperature crack growth phenomenon in power plant materials is presented. Various techniques developed for 
characterizing elevated temperature crack growth have been discussed with emphasis on data collection, analysis and interpretation of results. Essentially, fracture mechanics approaches have been presented. Creep crack growth (CCG) and creep-fatigue crack growth (CFCG) have been discussed in detail with emphasis on the latter. The discussion is primarily focussed on creep-ductile materials ${ }^{1}$. Special considerations for high-temperature crack growth in weldments have also been discussed. Finally, all these concepts have been applied to life prediction of power plant components like steam-turbine casings. This presentation is aimed to be application oriented. Some recommendations for future research in this area are also provided.

\section{Review of time-dependent crack-tip parameters}

Fracture mechanics approaches are extrapolative i.e. the results obtained using small laboratory specimens can be "extrapolated" to make predictions in actual components. Various crack-tip parameters have been proposed which characterize the state of stress at the crack tip. The underlying idea behind these crack-tip parameters is that they act as a 'transfer function' from a specimen in the laboratory to actual structural behaviour. Identical conditions of stress and deformation at the crack tip result in the same value of these crack-tip parameters regardless of the shape and size of the specimens or the structures.

When a cracked body is subjected to constant load at elevated temperatures, the initial stress-strain response due to sudden loading is similar to that under subcreep temperatures. A $1 / r^{1 / 2}$-type and HRR-type (Hutchinson-Rice-Rosengren type) singular stress field is formed in elastic and elastic-plastic materials, respectively. However, with the passage of time, creep strains (inelastic in nature) begin to accumulate. Their magnitude near the crack tip is relatively large because of the high level of initial stresses. This causes the crack-tip stresses to relax, and, the initial strong singularity at the crack-tip is relaxed to a weaker one governed by material creep behaviour.

Under the aforementioned conditions, the stress-intensity parameter, $K$, and the $J$-integral cannot be used to uniquely characterize the crack growth. This has led to the extensive development of time-dependent fracture mechanics (TDFM) concepts using analogy to the elastic-plastic fracture mechanics (EPFM) concepts (Riedel 1987; Saxena 1989). Three regimes of crack growth - small scale, transient and steady-state -are observed in creeping materials, depending on the size of the crack-tip creep zone relative to the specimen dimensions. Figure 1 (Saxena 1986) schematically defines these regimes. The reader is referred to Saxena $(1986,1991)$ for definitions and details. The best example of an analogy between TDFM and EPFM concepts is the relation between the creep strain rate and the stress for the steady-state creep regime in a creeping material. This relation is analogous to the relation between instantaneous plastic strain and stress in an elastic-plastic (EL-PL) material underfully plastic conditions. The first crack tip parameter defined in TDFM is $C^{*}$, which specifically addresses the steady-state (large-scale) creep crack growth regime. Crack tip parameters used in TDFM are discussed in the following sections.

\footnotetext{
${ }^{1}$ Creep-ductile materials are defined as those in which the crack growth is negligible compared to the creep zone expansion rate, i.e. these materials are highly susceptible to creep deformation.
} 


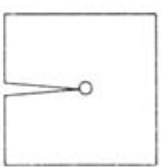

(a)

(b)

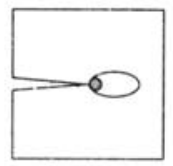

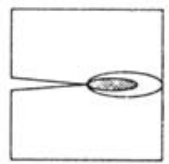

(c)

(d)

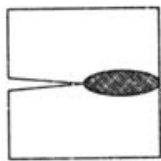

primary

secondary

Figure 1. Stages of creep deformation in cracked bodies subjected to primary and secondary creep deformation. (a) Small-scale primary creep conditions. (b) Secondary creep zone growing within the primary creep zone which is now comparable in size to the uncracked ligament. (c) Extensive primary creep conditions with a substantial secondary creep zone. (d) Extensive secondary creep conditions (from Saxena 1986).

\subsection{The $C^{*}$ parameter}

$C^{*}$ was defined (Landes \& Begley 1976; Nikbin et al 1976) as a path independent integral with direct analogy to the $J$-integral (Rice 1968) in EPFM.

$$
C^{*}=\int_{\Gamma} W^{*} \mathrm{~d} y-T_{i}\left(\partial \dot{u}_{i} / \partial x\right) \mathrm{d} s,
$$

where $W^{*}$ is the strain-rate-energy density given by

$$
W^{*}=\int_{0}^{\dot{i}_{i j}} \sigma_{i j} \mathrm{~d} \dot{\varepsilon}_{i j}
$$

In (1), $T_{i}$ is the traction vector defined by the outward unit normal vector $n_{j}$ along the path $\Gamma$, which is taken from any point along the lower crack surface, counter-clockwise around the crack tip to end at the top surface. $\sigma_{i j}$ and $\delta_{i j}$ are the stress and strain-rate tensors, $\dot{u}_{j}$ is the defiection-rate vector along the direction of the traction and $d s$ is the length along $r$. The physical significance of $C^{*}$ lies in that it represents the power difference between two identically loaded bodies having incrementally different crack lengths, i.e.

$$
C^{*}=-(1 / B)\left(\mathrm{d} U^{*} / \mathrm{d} a\right)
$$

where $U^{*}$ is the power (energy rate) input to the cracked body to grow the crack by an increment da. Equation ( 3 ) is also analogous to the physical significance of $J$. This makes $C^{*}$ measurable as a physical entity at the loading pins where the external load is applied. Further, its path-independence definition ensures that a unique $\sigma-\dot{\varepsilon}$ relationship holds in the near field of the crack tip as well as in the far field where the external load is applied. The stress and strain-rate fields at the crack tip are characterized by $C^{*}$ as follows:

$$
\begin{aligned}
& \sigma_{i j}=\left(C^{*} / A I_{n} r\right)^{1 /(n+1)} \tilde{\sigma}_{i j}(\theta), \\
& \dot{\varepsilon}_{i j}=A\left(C^{*} / A I_{n} r\right)^{n /(n+1)} \tilde{\varepsilon}_{i j}(\theta) .
\end{aligned}
$$


in (4) above, $C^{*}$ represents the intensity of the stress singularity at the crack tip (Goldman \& Hutchinson 1975). $r$ is the radial distance from the crack tip and $\theta$ is the angle from the plane of the crack. $I_{n}$ is a nondimensional constant and $\tilde{\sigma}_{i j}(\theta)$ and $\tilde{\varepsilon}_{i j}(\theta)$ are angular functions listed in Shih (1983). $A$ and $n$ are the steady-state creep constant and exponent, respectively, in the following constitutive law used to describe the unique relationship that exists between stress $(\sigma)$ and strain-rate $(\dot{\varepsilon})$ for a material undergoing secondary creep,

$$
\dot{\varepsilon}=A \sigma^{n} \text {. }
$$

In brief, $C^{*}$ satisfies the following characteristics which make it an attractive choice for a crack-tip parameter under large-scale (steady-state) creep conditions.

(a) It is associated with a path-independent integral, (1);

(b) it has a physical interpretation, (3), and can be measured at the loading pins;

(c) it characterizes the crack-tip stress and strain-rate fields, (4), (5).

However, due to its definition being analogous to the $J$-integral used under fullyplastic conditions, the usefulness of $C^{*}$ for characterization of $C C G$ is limited because it is not applicable under small-scale-creep conditions (SSC conditions) and transition creep conditions. Since most components in service are made from materials designed to resist large-scale creep, $C^{*}$ cannot be used to characterize creep crack growth in these components because SSC conditions dominate.

\section{$2.2 C(t)-$ integral}

Equation (6) can be modified to represent the creep behaviour of elastic-creeping materials as follows:

$$
\dot{\varepsilon}=(\dot{\sigma} / E)+A \sigma^{n},
$$

where, $E$ is the elastic modulus of the material. The dots represent the derivatives w.r.t. time. In accordance with (7), under transient creep conditions (non-steady state conditions) in elastic-creeping materials, strain-rate is a function of both time and stress at every point inside or outside the creep zone boundary because stress also varies with time. Hence, the integral defined in (1) is no longer path independent i.e. it varies for each contour, and even for the same contour the value of the integral varies with time resulting in a non-unique $\sigma-\dot{\varepsilon}$ relationship. Further, it no longer has the energy rate interpretation. Since crack-tip stresses also vary with time, $C^{*}$ does not uniquely characterize them under these conditions. Thus, it loses its utility as a crack-tip parameter.

The $C(t)$ - integral was defined to extend $C^{*}$ to the small-scale creep regime via its path-integral definition, (1). This involves selecting an integration path in the small creep strain dominated region, just ahead of the crack tip, contained within the elastic strain dominated fields. Thus, the integral defining $C^{*},(1)$, is path-independent and also characterizes the crack tip stress and strain rate singularities at any given time. This integral is the $C(t)$-integral. Under extensive creep conditions $C(t)=C^{*}$. These attributes make $C(t)$ a candidate parameter for characterizing CCG and CFCG. Details regarding the definition and evaluation of the $C(t)$-integral can be found in the literature (Ohje et al 1979; Riedel \& Rice 1980; Ehlers \& Riedel 1981). Recent numerical studies (Leung et al 1988; McDowell \& Leung 1988; Bassani et al 1989) have confirmed 
the validity of the expression proposed by Ehlers \& Riedel (1981) for evaluating $C(t)$ in the transition creep regime. However, the $C(t)$-integral cannot be related to the stress-power dissipation rate and cannot be measured at the loading-pins. This limits the practical use of $C(t)$ as a crack-tip parameter.

\section{$2.3 C_{t}$ - parameter}

In order to overcome the aforementioned limitations of $C^{*}$ and $C(t)$ parameters, $C^{*}$ was extended into the transient creep regime via its stress-power dissipation rate definition, (3), by Saxena (1986). $C_{t}$ represents the instantaneous stress-power dissipation rate during the transient while $C^{*}$ represents the steady state rate. $C_{t}$ is defined as follows:

$$
C_{t}=\lim _{\Delta a \rightarrow 0}\left(-\frac{1}{B} \frac{\Delta U_{t}^{*}}{\Delta a}\right)=-\frac{1}{B} \frac{\partial U_{1}^{*}}{\partial a}
$$

where $U_{t}^{*}$ is instantaneous stress-power (energy-rate). The subscript ' $t$ ' denotes that the value of $U$ is at a fixed time $t$. Thus, $C_{t}$ is defined in terms of the difference in the energy-rates (or power) supplied to two cracked bodies with identical creep deformation histories, but having cracks differing in length by $\Delta a$, as they are loaded to different deflection-rate levels. In other words, $C_{1}$ is the power supplied to a cracked body, undergoing creep deformation, at any instant of time to grow the crack infinitesimally. Further details are presented by Saxena (1986). Under transient creep conditions, the $C_{t}$-parameter does not characterize the singular crack tip stress fields but is uniquely related to the creep zone expansion rate (Saxena 1986).

Methods for evaluation of $C_{t}$ under small-scale and steady-state creep conditions are discussed in subsequent sections.

\subsection{Crack tip parameters for CFCG}

Under creep-fatigue type of loading, using trapezoidal or other waveshapes (figure 2) (Saxena 1993), elastic, plastic and creep deformation can occur at the crack tip. The extent of creep is governed by the rate of loading. The extent of creep deformation depends on the length of the hold period, while the extent of creep deformation during the loading part of the cycle is affected by the rate of loading. Stress redistribution occurs due to creep during the hold time and causes change in the elastic strains (Saxena 1993). If the hold time is sufficiently long, extensive creep conditions may occur whence the stress for a stationary crack becomes constant and further deformation occurs only by creep (Riedel \& Rice 1980; Saxena 1980; Bassani \& McClintok 1981). For the case of a trapezoidal wa veform involving fast loading followed by a significant period of sustained loading, the normalized crack tip stress as a function of normalized time at a fixed distance ahead of the crack tip is given as in figure 3 , taken from the work of Riedel (1993). Formulating analytical approaches for crack-tip stress analysis under CFCG conditions is not an easy task because the combinations of loading and material behaviour involved are complex, including effects due to cyclic plasticity mixed with primary and secondary creep deformation. Consequently, numerical approaches are frequently employed (Saxena 1993). Also, the CFCG experimental studies carried out for explaining CFCG behaviour outnumber the analytical studies. These experimental 


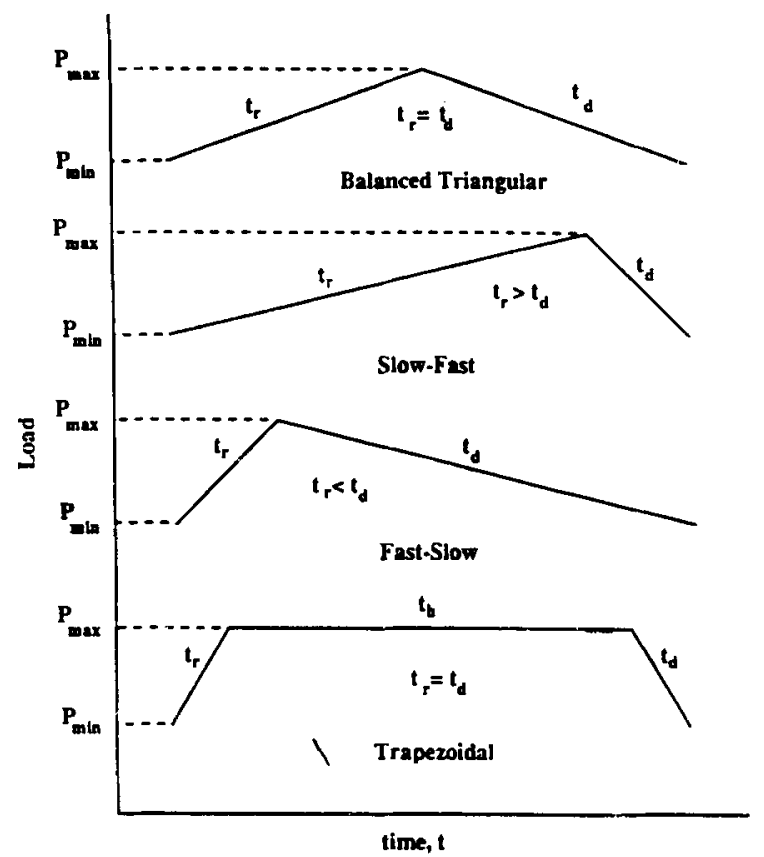

Figure 2. Typical loading waveforms used during creeplatigue crack growth testing in the.laboratory.

studies have resulted in the identification of relevant crack tip parameters. The discussion here will focus on the $\Delta J_{c}($ Ohtani et al 1981, 1989; Ohji 1986; Kuwabara et al $1988)$ and the $\left(C_{t}\right)_{\text {avg }}$ (Saxena \& Gieseke 1990) parameters.

For trapezoidal waveform with rapid loading/unloading as compared to the hold time, $\Delta J_{c}$ is given by (Ohtani et al 1981, 1989; Ohji 1986; Kuwabara et al 1988)

$$
\Delta J_{c}=\int_{0}^{t_{h}} J^{*} \mathrm{~d} t,
$$

where $J^{*}$ is identical to $C^{*}$ described in $\S 2 \cdot 1, t_{h}$ is the hold time.

$\left(C_{t}\right)_{\text {avg }}$ is defined as (Saxena \& Gieseke 1990; Yoon et al 1992, 1993)

$$
\left(C_{t}\right)_{\text {avg }}=\frac{1}{t_{h}} \int_{0}^{t_{h}} C_{t} \mathrm{dt},
$$

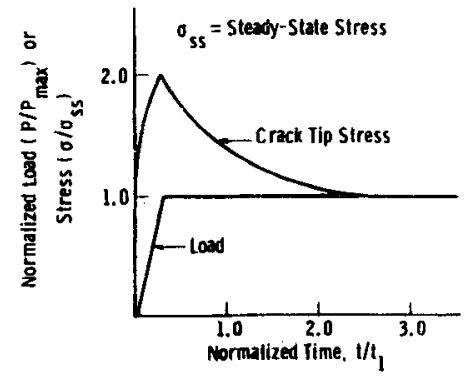

Figure 3. Normalized crack tip stress as a function of normalized time at a fixed distance ahead of the crack tip for fast loading followed by sustained load (from Riedel 1983). 
for materials showing "creep reversal" i.e. the creep deformation is significantly reversed during every cycle because these materials have low resistance to cyclic plasticity. For materials that do not exhibit creep reversal effects, $C_{t}$ is not reinstated after each cycle. The following expression is used to calculate $\left(C_{t}\right)_{\text {avg }}$ for such materials (Adefris 1993),

$$
\left(C_{t}\right)_{\mathrm{avg}}=\frac{1}{t_{h}} \int_{N-1}^{N} C_{t} \mathrm{~d} t .
$$

As mentioned in the previous section, under extensive creep conditions, $C_{\text {, and }} C^{*}$ (or $\left.J^{*}\right)$ are the same by definition. Hence, (9) and (10) imply that $\Delta J_{\mathrm{c}}$ and $\left(C_{t}\right)_{\text {avg }}$ are uniquely related in the extensive creep regime as:

$$
\Delta J_{c}=t_{h}\left(C_{t}\right)_{\text {avg }}
$$

Under conditions of small scale creep $C_{t}$ and $C^{*}\left(\right.$ or $\left.J^{*}\right)$ are not the same. However, in the case of correlations based on experimental measurements of these parameters, differences in the numerical values of the two are not significant (Saxena 1986; Bassani et al 1989). On the other hand, if the parameters are calculated, significant differences could result if the influence of small-scale-creep conditions is not included in the calculations of $C_{t}$. Thus, $\left(C_{t}\right)_{\text {avg }}$ and $\Delta J_{c}$ differ significantly, and, in general, are not related by (12).

In summary, $\left(C_{t}\right)_{\text {avg }}$ and $\Delta J_{c}$ parameters are equivalent under extensive creep conditions but not under small-scale-creep conditions where $\Delta J_{c}$ can only be operationally defined (Saxena 1993). The operational definition of $\Delta J_{c}$ is based on experimental load-line deflection measurements (Saxena 1993). Thus, $\left(C_{t}\right)_{\text {avg }}$ is the more widely applicable parameter.

\section{Test methods and crack growth data}

Test methods for conducting CCG and CFCG tests are discussed in the following sections along with the data collection and data reduction steps. Insights into the analysis of these data is also provided. An accelerated test procedure (Grover \& Saxena 1994) recently proposed for CFCG testing is discussed in some detail.

\subsection{Creep crack growth testing and data analysis}

The objective of creep crack growth testing, according to the ASTM (1992) standard on creep crack growth testing, is to determine the relationship between the time rate of crack growth, $\mathrm{d} a / \mathrm{d} t$, and the applied value of the $C^{*}(t)$-integral, where $C^{*}(t)$ is the time-dependent value of $C^{*}$ defined in (1) and has been defined to extend the validity of $C^{*}$ into the extensive primary creep regime (Saxena 1989a, 1991). The creep crack growth rates expressed as a function of $C^{*}(t)$ characterize the resistance of a material to crack growth under extensive creep conditions. However, it has been shown (Riedel \& Detampel 1987; Saxena 1989a), as discussed later, that $C_{\text {t }}$ correlates the $\mathrm{d} a / \mathrm{d} t$ data better than $C^{*}(t)$ and it characterizes the creep crack growth resistance of a material under a wide range of creep conditions, including small-scale creep and transition creep conditions. Hence, $C_{t}$ is the crack-tip parameter of choice in this study.

A variety of specimen geometries are used in fracture mechanics studies to simulate the service loading conditions in the laboratory. Some of these are illustrated in figure 4. 

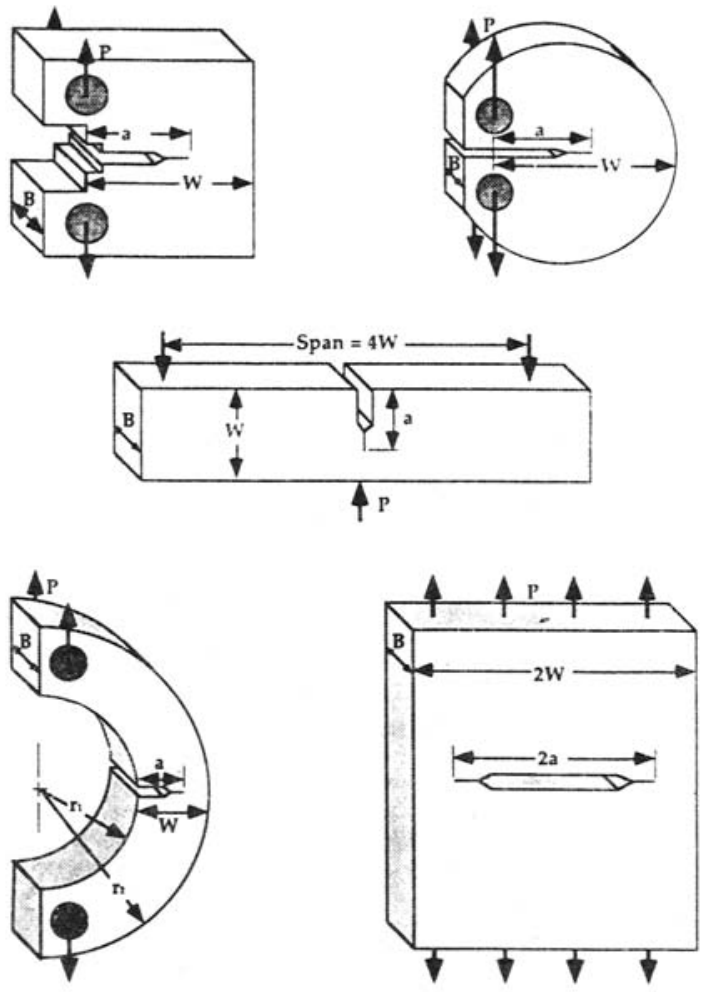

Figure 4. Typical specimens used in fracture mechanics for testing, after Anderson. (1991) (a) Compact specimen. (b) Disk shaped compact specimen. (c) Single edge notched bend (SENB) specimen. (d) Arc shaped specimen. (e) Middle tension (MT) specimen.

Compact type (CT) and the centre cracked tension (CCT) specimens are commonly used. However CT specimens are the preferred geometry for CCG and CFCG studies, to be discussed later. They require lower load levels and the transition time for steady-state conditions to develop from SSC conditions is longer for CT specimens than for CCT specimens having comparable widths. Thus, CT specimens are better suited for longer elevated temperature tests. Further, a displacement gauge can be conveniently placed at the load-line of a CT specimen for measuring the load-line deflection. The schematic in figure 5 (ASTM 1992) shows a deflection gauge placed at the load-line in a CT specimen.

Specimens are pre-cracked using fatigue loading. They are subjected to dead-weight loading at test temperature in suitable furnaces. The crack length and the load-line displacements are continuously recorded as a function of time. Electric potential drop method ( $\mathrm{DC}$ or $\mathrm{AC}$ ) is usually used to measure crack lengths. These data can be collected digitally using a suitable data-acquisition system, or it can be recorded on a strip-chart recorder. The latter is usually used as a backup even when a dataacquisition system is used. Monitoring of the temperature is required to ensure that it remains constant within allowable limits during the test. A record of load versus time must be maintained if servo-mechanical loading systems are used to achieve constant load conditions (ASTM 1992).

The load, load-line displacement and the crack length data are subsequently processed to obtain the correlations between the creep crack growth rates and a crack 


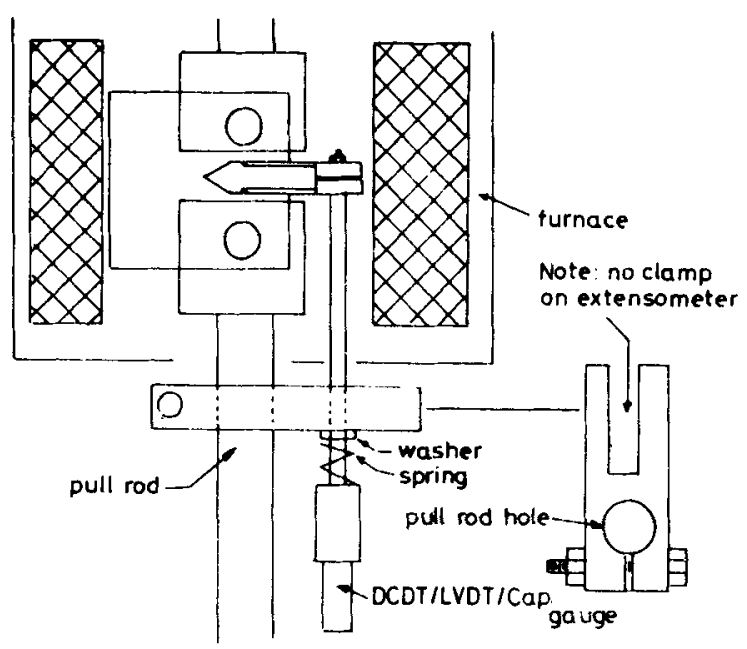

Figure 5. Schematic of the overall test set-up showing the clip gauge as attached to the specimen (from ASTM 1992).

tip parameter, $C_{t}$ in this study. Expressing $\mathrm{d} a / \mathrm{d} t$ as a function of $C_{t}$ generally provides results that are independent of the specimen size and planar geometry for the same crack-tip stress state. This is useful in comparing data from a variety of specimen configurations and loading conditions. Assuming similitude, i.e. that cracks of different length subjected to the same nominal value of $C_{t}$ advance by equal increments of crack extension per unit time, the data obtained from these tests can be utilized in the design and evaluation of engineering structures operated at elevated temperatures. Material selection criteria and inspection requirements for damage tolerant applications can also be established using this data. However, results from these tests should not be applied to cracks in structures with wide-spread creep damage around the crack tip.

The crack growth rates are calculated from the crack length versus time ( $a$ vs $t$ ) data. $C_{t}$ is calculated for a wide range of creep conditions from the load-line deflection rates in the specimen using the following expression,

$$
C_{t}=\frac{P \dot{V}_{c}}{B W} \frac{F^{\prime}}{F}+C^{*}(t)
$$

where, $P$ is the load applied to the specimen having width $W$ and thickness $B . F$ is the $K$-calibration factor $=(K / P) B W^{1 / 2}$ and $F^{\prime}=\mathrm{d} F / \mathrm{d}(a / W) . V_{c}$ is the contribution to the measured load-line deflection rate due to creep. It is obtained using (14) (Saxena 1986, 1991; ASTM 1992).

$$
\dot{V}_{c}=\dot{V}-(\dot{a} B / P)\left[\left(2 K^{2} / E\right)+(m+1) J_{p}\right]-\dot{\mathrm{P}} C,
$$

where $\dot{a}$ is the crack growth rate, $J_{p}$ is the plastic part of $J$ calculated from expressions provided in Riedel \& Detampel (1987), $m$ is the plasticity constant of the material, $C$ is the machine compliance. For constant load tests, the load rate, $P=0$ and the last term on the right hand side of (14) drops out.

$C^{*}(t)$ in (13) can also be measured in test specimens (Lee 1987),

$$
C^{*}(t)=\left(P \dot{V}_{c} / B W\right) \eta\left(a / W, n, n_{1}\right)
$$


where $\eta$ is a function of the crack size to width ratio, $a / W$, the secondary and primary creep constants, $n$ and $n_{1}$ respectively. For practical purposes, for CT specimens it is defined as (Saxena 1991)

$$
\eta=[n /(n+1)]\{[2 /(1-a / W)]+0 \cdot 522\} .
$$

However, the term $n /(n+1)$ on the right hand side is strictly valid for secondary creep only and it has to be replaced by $n_{1} /\left(n_{1}+1\right)$ when most of the time is spent under primary creep conditions (Saxena 1991). Further details on this issue are provided in Saxena (1991).

\subsection{Experimental correlations of creep crack growth data}

In this section, experimental evidence is provided in support of the suitability of the $C_{t}$ parameter over other crack tip parameters, $C(t)$ and $C^{*}$, for characterizing $C C G$. The creep crack growth trends of austenitic and ferritic steels used at elevated temperatures are also discussed.

Figures 6 to 8 (Saxena 1989a) show plots of the creep crack growth rate, $\mathrm{d} a / \mathrm{d} t$, as a function of $C^{*}, C(t)$ and $C_{t}$ respectively. The data shown include that from tests where transient conditions prevailed for significant lengths of time before the steady state

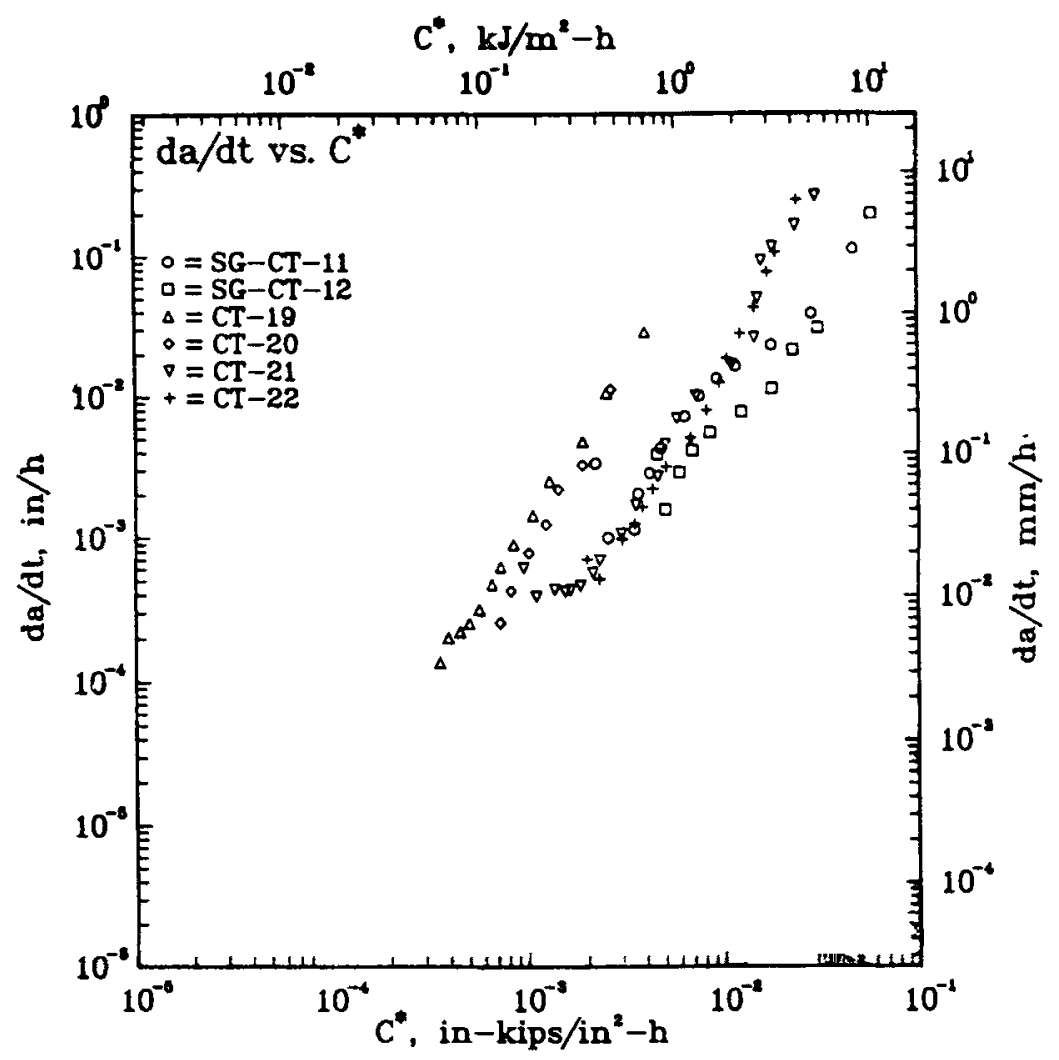

Figure 6. Creep crack growth rate as a function of $C^{*}$ (from Saxena 1989a). 


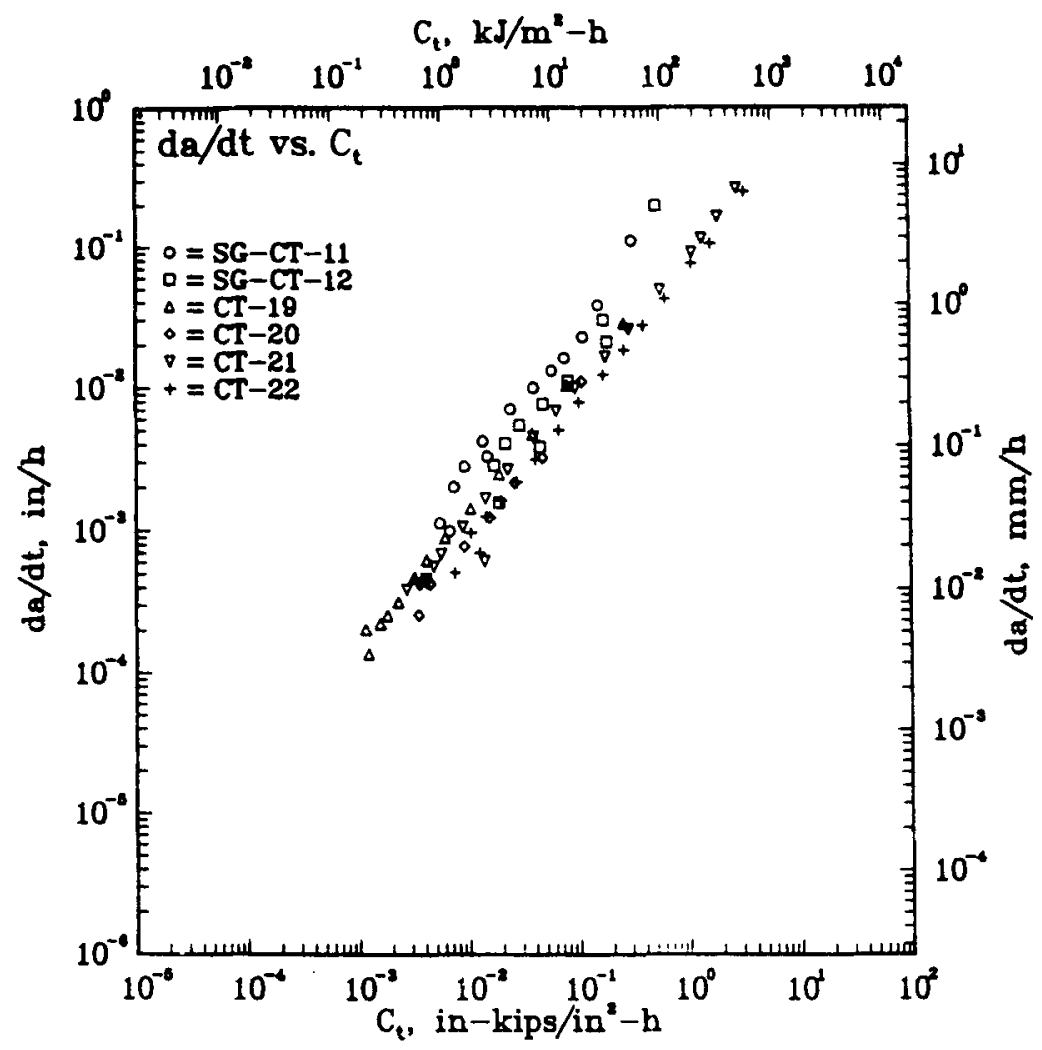

Figure 7. Creep crack growth rate as a function of the $C(t)$ parameter, in a Cr-Mo V steel (from Saxena 1989a).

conditions were reached. It can be clearly seen that the data do not correlate well with either $C^{*}$ or $C(t)$ while it does with $C_{t}$. Riedel \& Detampel (1987) have also shown $C_{t}$ to be the parameter of choice for correlating creep crack growth rate (CCGR) data. For further discussion, readers are referred to Saxena (1989a).

Creep cracks in most high temperature steels grow by grain boundary cavitation and the effect of the environment is minimal. Figure 9 (Saxena 1989a) shows the CCG behaviour of ex-service and new $\mathrm{Cr} \cdot \mathrm{Mo}$ and $\mathrm{Cr}-\mathrm{Mo} \mathrm{V}$ steels commonly used in power plants. Despite the varying material compositions and thermal histories of these materials, their CCG behaviours show similarity and almost all the data lie within a $95 \%$ confidence scatter band. Correlating CCG rates with $C_{t}$ (or $C^{*}$, for only steady state conditions) provides a first-order normalization with respect to changes in temperature, provided there is no substantial change in the rupture ductilities due to changes in temperature, composition, or thermal history (Saxena 1989a). Thus, CCGR data at different temperatures show the same trend when correlated with $C_{\text {t }}$ even though the creep deformation rates at those temperatures for the material are very different. This is illustrated in figure 10, while figure 11 shows the creep deformation behaviour of the material (Saxena 1989a). This lack of temperature dependence of the $\mathrm{d} a / \mathrm{d} t$ vs $C_{t}$ plots is useful because the life predictions made for a component operating at one temperature would be valid for its operation at a different temperature. Further, 


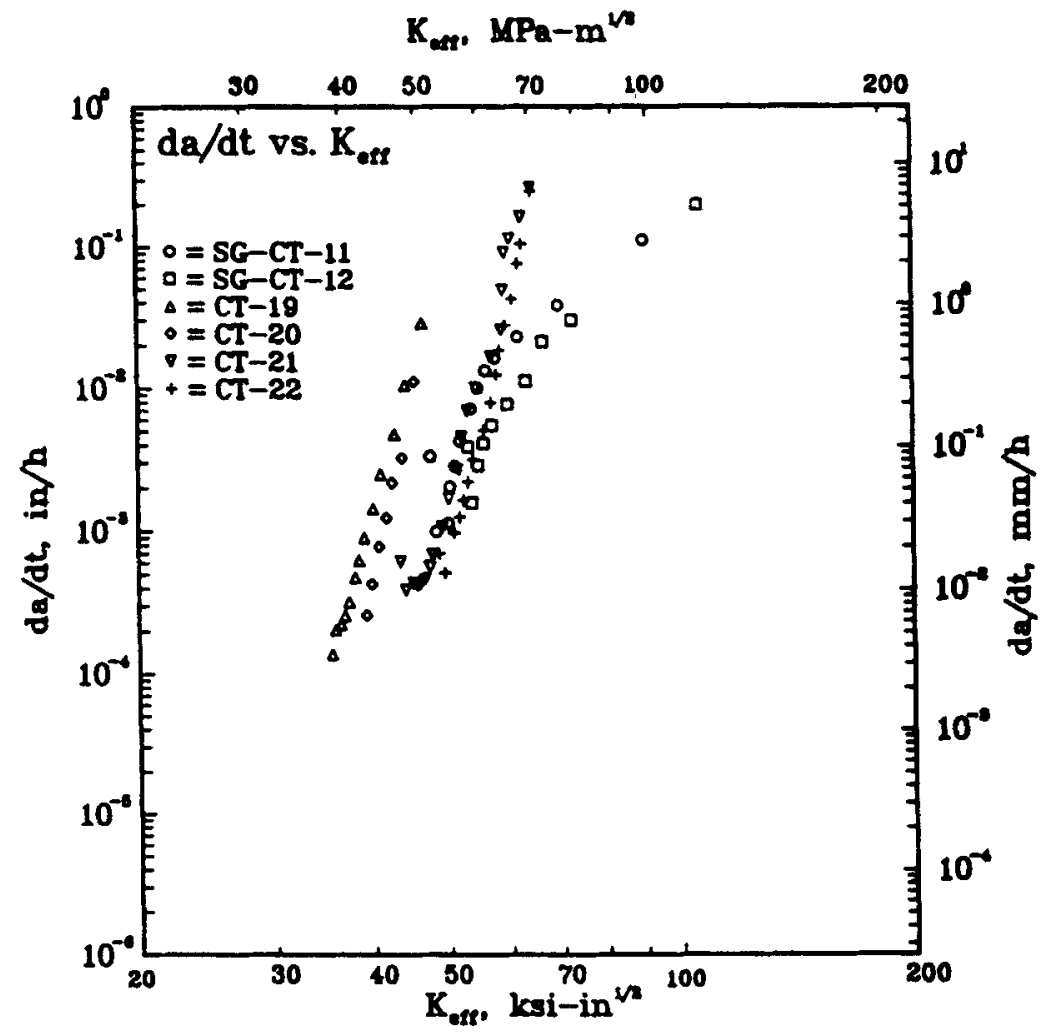

Figure 8. Creep crack growth rate as a function of $C_{t}$ (from Saxena 1989a).

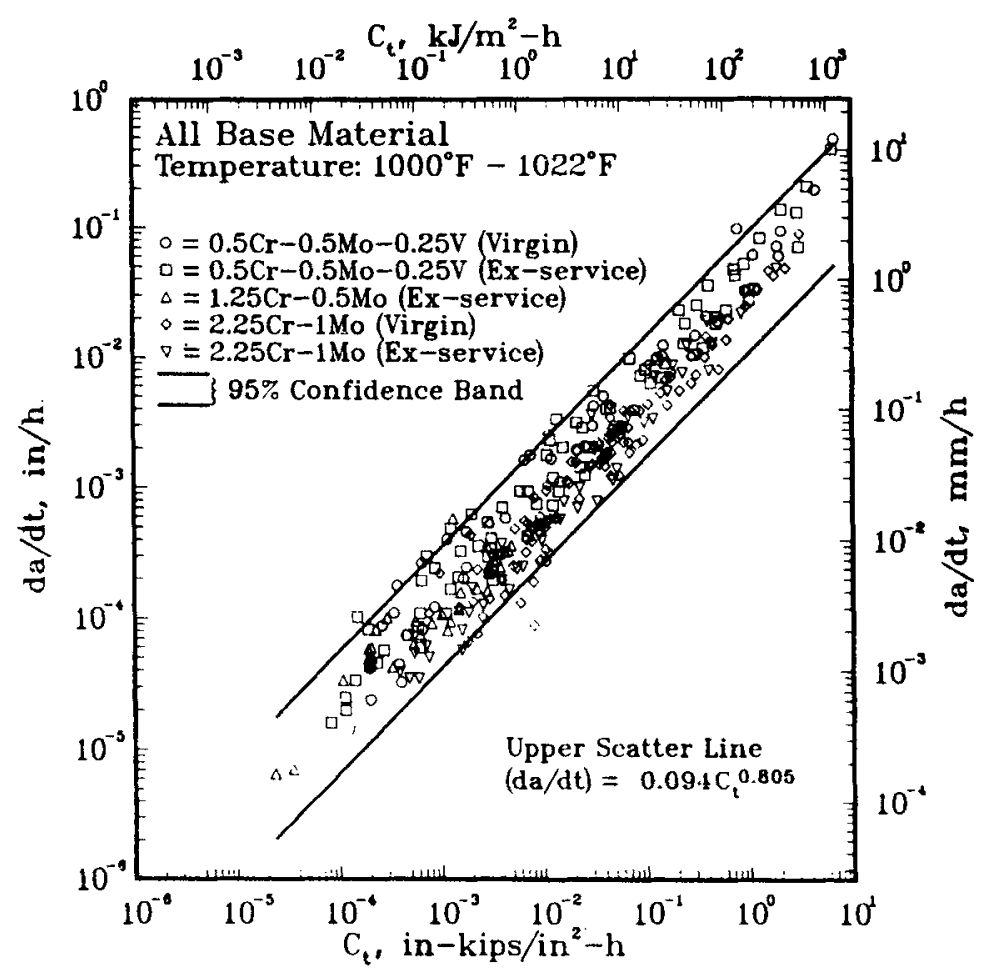

Figure 9. Creep crack growth behaviour of $\mathrm{Cr}-\mathrm{Mo}$ and $\mathrm{Cr}-\mathrm{Mo}-\mathrm{V}$ base material. The data include all ex-service and new material data (from Saxena 1989a). 


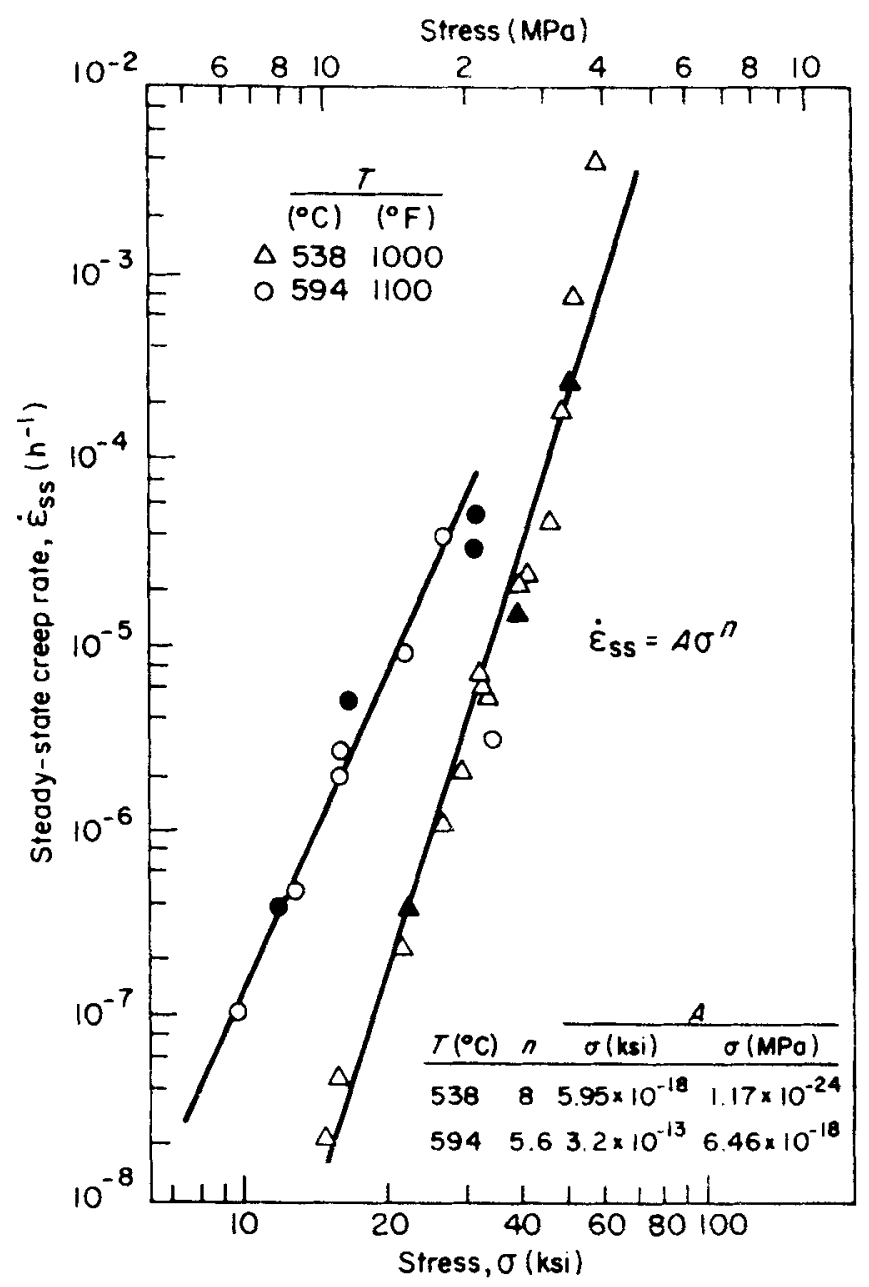

Figure 10. Creep crack growth behaviour of $1 \mathrm{Cr} \cdot 1 \mathrm{Mo} \cdot 0.25 \mathrm{~V}$ steel as a function of temperature (from Saxena 1989a).

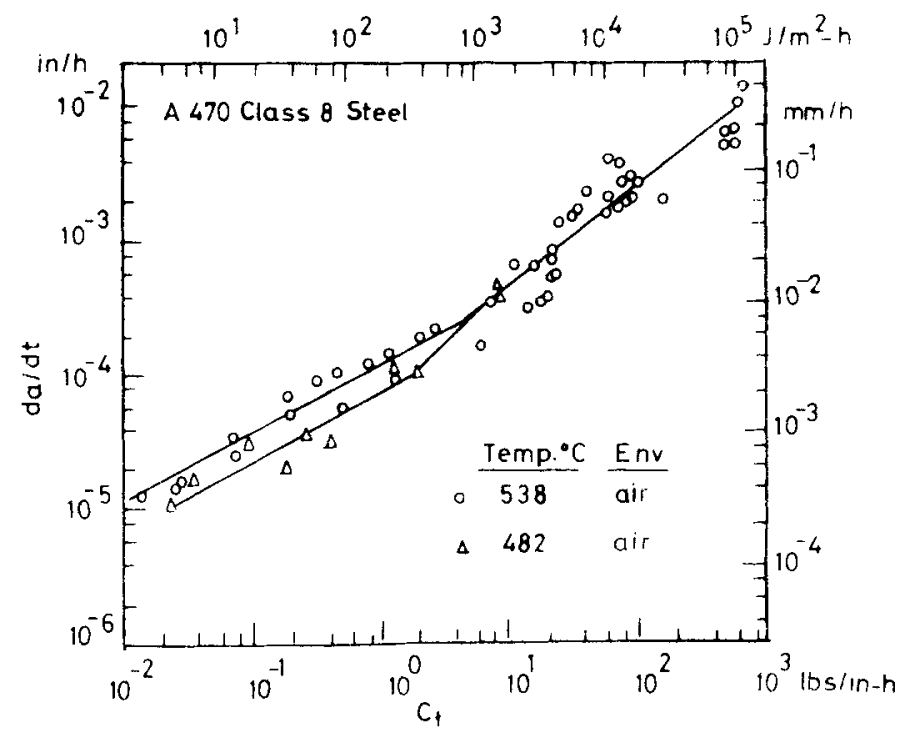

Figure 11. Creep deformation behaviour of A470 class 8 steel (from Saxena 1989:1). 
if the CCGR data for a certain temperature are not available, design parameters can be decided and life predictions for the component can be made on the basis of the CCGR data for a different temperature. However, service conditions may result in a significant change in the creep ductilities causing the $\mathrm{d} a / \mathrm{d} t$ vs $C_{t}$ relationship to change with temperature and it may be different for two parts of the same component subjected to different temperatures. This is generally due to the microstructural changes in the material resulting from exposure to varying service temperatures. An example of this is the higher CCGR that results in the "hot end" of a steam header as compared to its "cold end", due to the coarsening of grain boundary carbides under the higher operating temperatures of the hot end.

\subsection{Creep fatigue crack growth testing and data analysis}

Under creep fatigue crack growth conditions, crack growth occurs due to both creep and fatigue processes. A trapezoidal waveform simulates creep fatigue loading conditions. Creep deformation occurs mainly during the sustained loading period, the hold time $\left(t_{h}\right)$, while fatigue processes contribute to the crack growth during the loading part (rise time $-t_{r}$ ) and unloading part (decay time $-t_{d}$ ) of the trapezoidal wave, provided the rise and decay times are small in comparison to the hold time. However, if the loading rate at high temperatures is slow, creep can occur during the loading part of the cycle as well.

Unlike the ASTM (1992) standard for CCG testing, a standard test method has not been adopted for CFCG testing as yet. However, CFCG test methods and data analysis techniques have been discussed in detail by Grover \& Saxena (1994).

Accelerated CFCG tests lasting a few days to a few weeks are conducted to obtain data that are used to predict service behaviours up to 30-40 years.

CT specimens are the preferred geometry for CFCG testing due to reasons discussed earlier. Their size is determined on the basis of the amount of material available, the desired orientation of the crack, the size/shape of the available furnaces and the load-line deflection gauge to be used. The specimens are mounted on clevises placed in high temperature chambers/furnaces to heat them to the desired temperature. This is generally the same as the service temperature although higher temperatures may be used to decrease the test time, provided the creep deformation processes remain the same. Servohydraulic machines are used for loading the specimens under the desired waveform.

The trapezoidal waveform, mentioned earlier, is most commonly used because it simulates actual service conditions, especially in power plant materials. Figure 12 (Lee 1987) shows the stress as a function of time for various locations in a steam header. Having selected the waveform, the $K$-level/load levels are decided on the basis of the crack growth rates required during the test. These crack growth rates should be approximately those encountered by the material during service (Grover $\&$ Saxena 1994). However, often the time constraints on the duration of a test dictate the choice of the crack growth rates to be achieved during the test. Thus $K$-levels, have to be chosen in conjunction with the hold times of the loading waveform (Grover \& Saxena 1994). Other than the $K$-levels to be used, the sensitivity of the load-line deflection measurement gauge/amplifier system also affects the choice of the hold times. The reader is referred to Grover \& Saxena (1994) for further details. 

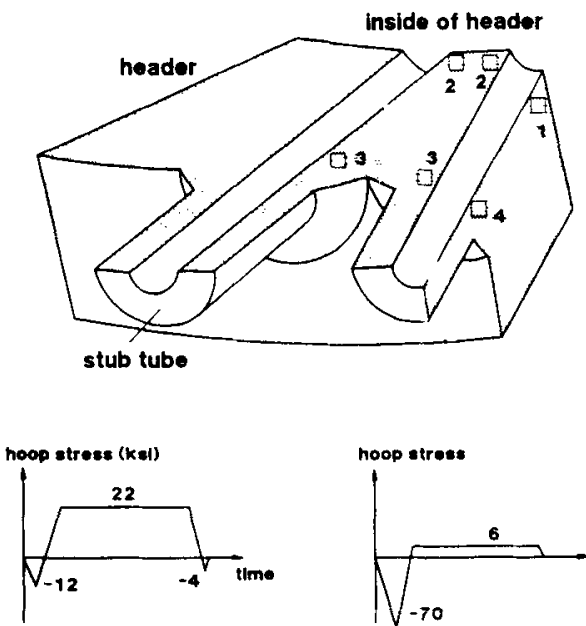

LOCATION 1

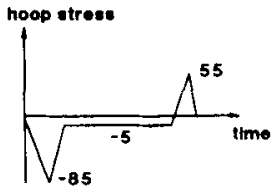

LOCATION 3

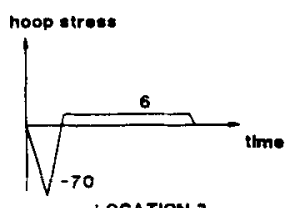

LOCATION 2

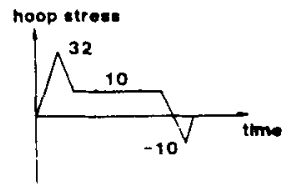

LOCATION 4
Figure 12. Stress versus time histories at different locations in a steam header.

The measurements made during the test are the deflection change during hold time, the total load-line deflection and the crack length at different stages in the test. It is advisable to monitor the load during hold time to ensure that the deflection changes are not due to random variations in the load (Grover \& Saxena 1994). Strip chart recorders or computerized data acquisition systems can be used to record the aforementioned data. Strip charts are useful because the deflection change traces can be visually inspected for the quality of the data. As in the case of CCG tests, crack length is measured using electric potential drop. Details on the DC potential drop method are given in ASTM (1991).

In order to obtain the influence of creep, the crack length data is reduced to time dependent crack growth rates, $\mathrm{d} a / \mathrm{d} t$. The average values of these, $(\mathrm{d} a / \mathrm{d} t)_{\text {avg }}$, are plotted against $\left(C_{1}\right)_{\mathrm{avg}}$, which is the average value of $C_{1}$. The average of $C_{1}$ is used to correlate CFCG data because of the experimental limitations involved in measuring $C_{t}$ during hold times.

$\left(C_{t}\right)_{\text {avg }}$ is evaluated using the measured load-line deflection change rate during the hold time as follows:

$$
\left(C_{t}\right)_{\mathrm{avg}}=\frac{\Delta P \Delta V_{c}}{B W t_{h}} \frac{F^{\prime}}{F}-\left(\frac{F^{\prime}}{F} \frac{1}{\eta}-1\right) C^{*}(t)
$$

where $\Delta P$ is the applied load range and $\Delta V_{c}$ is the load-line deflection change due to creep during hold time $t_{h}$. Rest of the terms are as defined earlier.

$\Delta V_{c}$ is obtained from the total measured deflection change, $\Delta V$, using the following expression.

$$
\Delta V_{c}=\Delta V-\frac{B t_{h}}{P}\left(\frac{\mathrm{d} a}{\mathrm{~d} t}\right)_{\mathrm{avg}}\left[\frac{2 K_{\mathrm{eff}}^{2}}{E}+(m+1) J_{p}\right],
$$


where $m$ is the plasticity exponent in the Ramberg-Osgood equation and $P$ is the applied load level. $K_{\text {eff }}$ is the value of $K$ corresponding to the 'effective' crack length corrected for plasticity.

It is noted that the $\Delta V_{c}$ value which is obtained using (18), from the total load-line deflection change, $\Delta V$, by deflection partitioning approach (Saxena et al 1983) includes both primary and secondary creep contributions to the load-line deflection change. $J_{p}$ is the fully plastic part of $J$ and is obtained from expressions listed in Kumar et al (1981). $C^{*}(t)$ can be determined using procedures outlined in Kumar et al (1981) and must include the contributions of secondary and primary creep. The $(\mathrm{d} a / \mathrm{d} t)_{\text {avg }}$ is calculated using

$$
\left(\frac{\mathrm{d} a}{\mathrm{~d} t}\right)_{\mathrm{avg}}=\frac{1}{t_{h}}\left[\left(\frac{\mathrm{d} a}{\mathrm{~d} N}\right)-\left(\frac{\mathrm{d} a}{\mathrm{~d} N}\right)_{\text {cycle }}\right],
$$

where $(\mathrm{d} a / \mathrm{d} N)_{\text {cycle }}$ is the cyclic crack growth rate and has to be obtained from a FCGR test carried out for which the rise and decay times are same as the trapezoidal waveform used in the CFCG tests.

The effects of fatigue on the crack growth are studied by obtaining correlations between the cycle dependent crack growth rate, $(\mathrm{d} a / \mathrm{d} N)_{\text {cycle }}$, and $\Delta K$, which is expressed as

$$
\Delta K=\left(\Delta P / B W^{1 / 2}\right) F(a / W) .
$$

All terms in the expression have been defined earlier.

The overall crack growth rate during a fatigue cycle, $\mathrm{d} a / \mathrm{d} N$, is defined as

$$
\frac{\mathrm{d} a}{\mathrm{~d} N}=\left(\frac{\mathrm{d} a}{\mathrm{~d} N}\right)_{0}+\int_{0}^{t_{\mathrm{h}}}\left(\frac{\mathrm{d} a}{\mathrm{~d} t}\right) \mathrm{d} t,
$$

and is measured during a CFCG test.

\subsection{Experimental correlations and modelling of CFCG data}

This section includes a discussion on the experimental correlations of CFCG data and the development of life prediction models for components using this data.

Figure 13 (Grover 1993) shows plots of $\mathrm{d} a / \mathrm{d} N$ vs $\Delta K$ for a $2 \cdot 25 \mathrm{Cr}-1.0 \mathrm{Mo}$ steel at $594^{\circ} \mathrm{C}\left(1100^{\circ} \mathrm{C}\right)$. The regression line through the FCGR $\left(t_{h}=0\right)$ is used to get the cycle-dependent part in modelling the CFCG data. The lack of correlation between $\mathrm{d} a / \mathrm{d} N$ and $\triangle K$ for the CFCG tests is evident from the scatter in the data in this figure. Such lack of correlation has also been shown in $\mathrm{Cr}-\mathrm{Mo}-\mathrm{V}$ steel, figure 14 (Harrison \& Sandor 1971). A discussion on the limitations of using $\Delta K$ for correlating high temperature crack growth is presented in (Saxena 1988, 1993; Grover 1993). An increase in the $\mathrm{d} a / \mathrm{d} N$ with increasing hold time for fixed $\Delta K$ is observed in figures 13 and 15 (Saxena \& Bassani 1984). This is due to the increasing contribution of timedependent crack growth (Grover \& Saxena 1994). Creep damage at the crack tip, influence of the environment, or microstructural changes such as formation of cavities which occur during loading at elevated temperatures could be responsible for this behaviour (Saxena 1993).

The average time dependent crack growth rates, $(\mathrm{d} a / \mathrm{d} t)_{\mathrm{avg}}$, are correlated with $\left(C_{t}\right)_{\text {avg. }}$. Figures 16 (Grover 1993) and 17 (Yoon et al 1993) show plots of $(\mathrm{d} a / \mathrm{d} t)_{\text {avg }}$ vs 


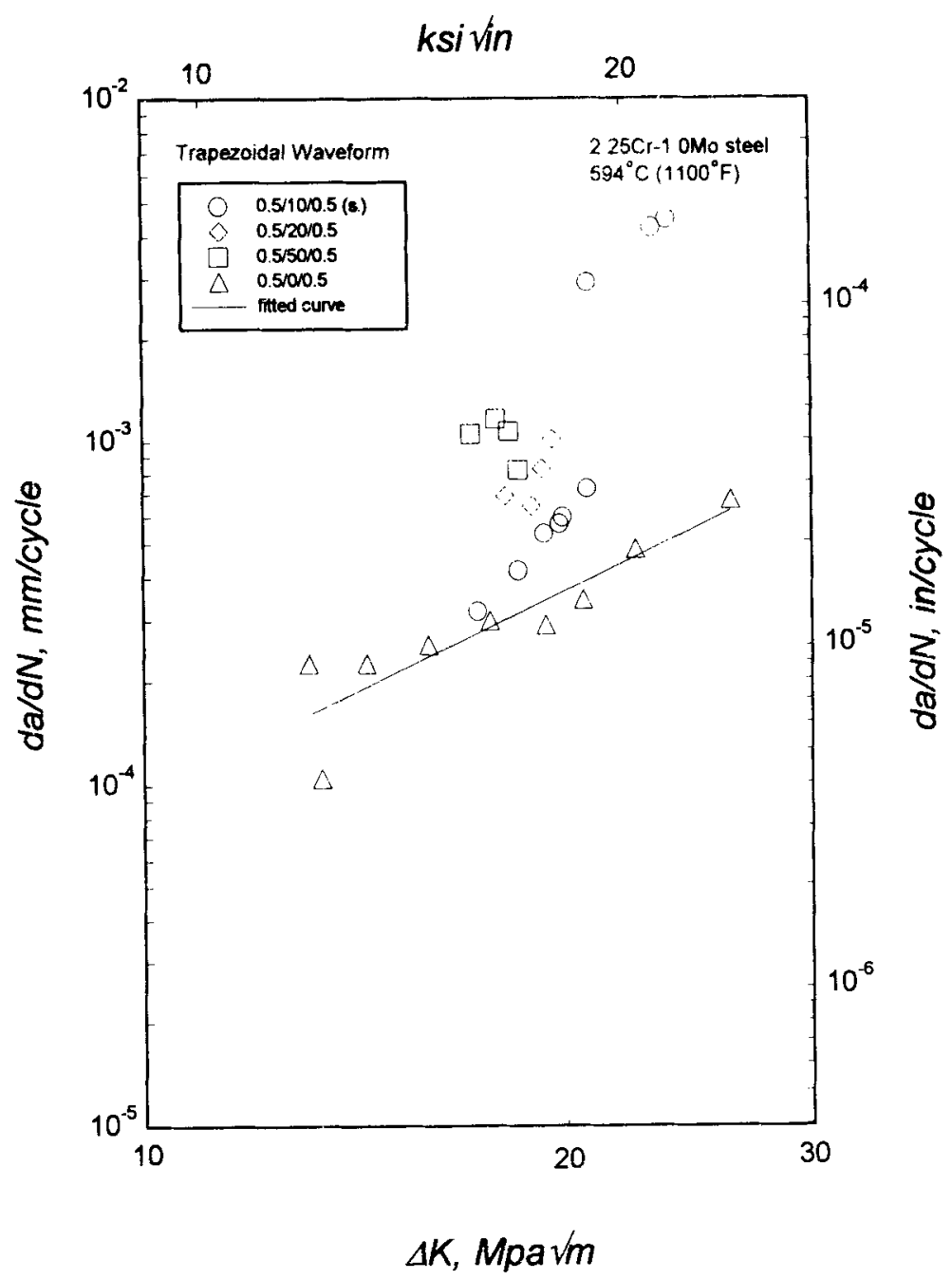

Figure 13. Fatigue crack growth data with various hold times and without hold time (from Grover 1993).

$\left(C_{1}\right)_{\text {avg }}$ for $2 \cdot 25 \mathrm{Cr}-1.0 \mathrm{Mo}$ and $1.25 \mathrm{Cr}-0.5 \mathrm{Mo}$ steels, respectively, for various hold times at elevated temperatures. All data show a clear trend and fall into a narrow scatter band despite the range of hold times used. This strongly indicates the usefulness of $\left(C_{t}\right)_{\text {avg }}$ in characterizing $\mathrm{CFCG}$ rates. Further, the $\mathrm{CCG}$ data for each of these materials have also been plotted on these graphs. However, $\mathrm{d} a / \mathrm{d} t$ has been correlated with $C_{t}$ for the CCG data. All the CCG and CFCG data show the same trend. This has the important implication that life prediction procedures for these materials would be considerably simplified because CCG data could be used to predict the life of components under CFCG conditions and vice-versa. In comparing a $(\mathrm{d} a / \mathrm{d} t)_{\mathrm{avg}}$ vs $\left(C_{t}\right)_{\mathrm{avg}}$ relation of CFCG with a $\mathrm{d} a / \mathrm{d} t$ vs $C_{t}$ relation of $\mathrm{CCG}$, it must be kept in mind that although $C_{t}$ and $\left(C_{t}\right)_{\text {avg }}$ are equivalent parameters with the same physical interpretation, their exact values may differ slightly in the SSC regime by a constant factor for a given material (Yoon et al 


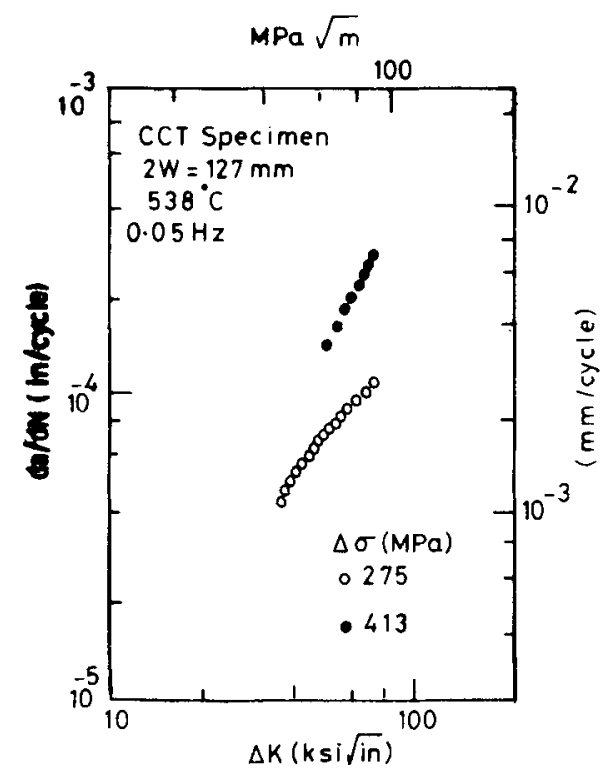

Figure 14. Elevated temperature fatigue crack growth behaviour of $\mathrm{Cr}-\mathrm{Mo}-\mathrm{V}$ steel plotted as a function of $\Delta K$ (from Harrison \& Sandor 1971).

1993). The value of this constant ranges from 1 to 1.3 for different materials, and further details are also presented (Yoon et al 1993).

The time dependence of the life-prediction model is obtained by generating a regression line through all the data. The total fatigue crack growth rate per cycle is

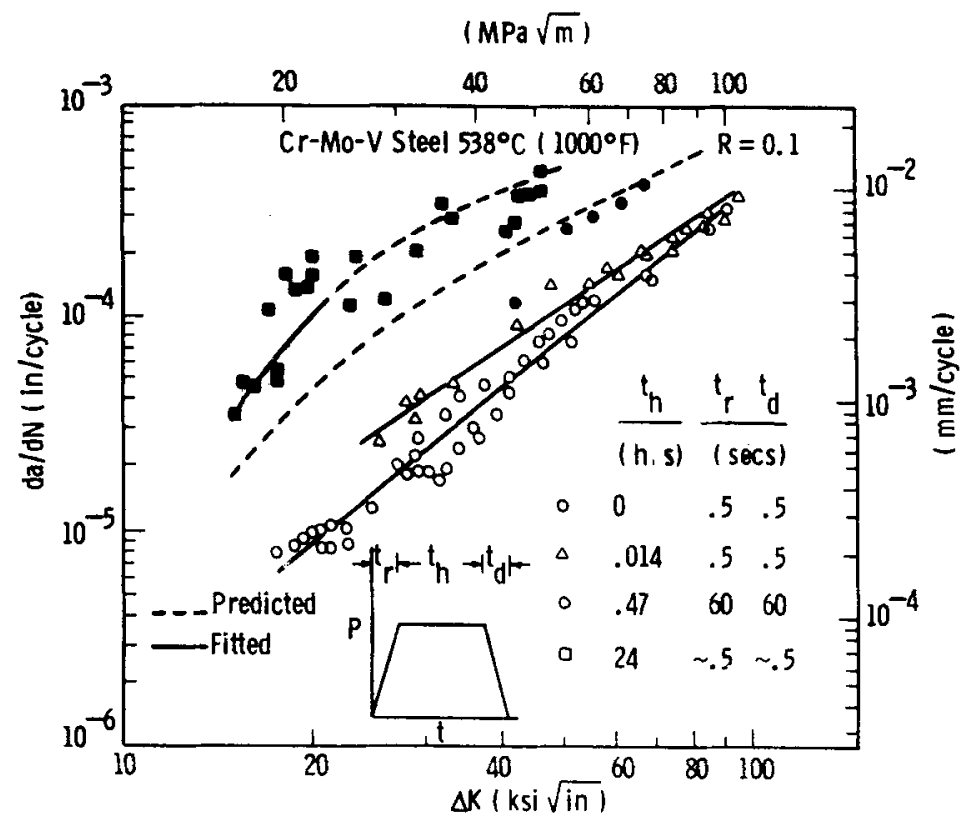

Figure 15. Effect of hold time of the fatigue crack growth behaviour of a $\mathrm{Cr}$ Mo--V steel (from Saxena et al 1984). 


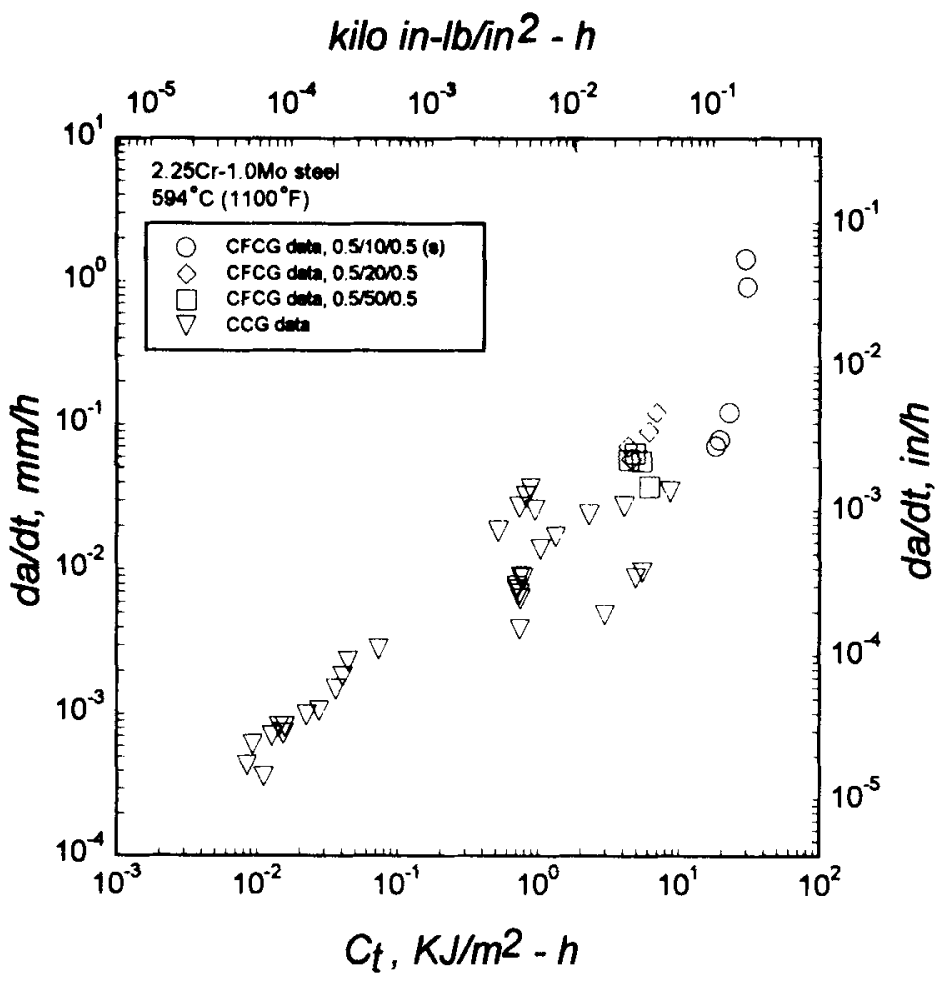

Figure 16. Correlation of crack growth rates with the measured values of $C_{t}$. (The average values of $\mathrm{d} a / \mathrm{d} t$ and $C_{\mathrm{r}}$ are plotted for CFCG data, from Grover 1993).

a linear summation of the cycle and time-dependent crack growth rates. Such an expression obtained for $2.25 \mathrm{Cr}-1.0 \mathrm{Mo}$ steel at $594^{\circ} \mathrm{C}\left(1100^{\circ} \mathrm{F}\right)$ under trapezoidal loading waveshapes is given in (22),(23) (Grover \& Saxena 1994) which are expressed in SI and British units, respectively.

$$
\begin{aligned}
& \mathrm{d} a / \mathrm{d} N=1.08 \times 10^{-6} \Delta K^{1.94}+1.46 \times 10^{-2}\left[\left(C_{t}\right)_{\mathrm{avg}}\right]^{0.722} t_{\mathrm{h}} \\
& \mathrm{d} a / \mathrm{d} N=5.11 \times 10^{-8} \Delta K^{1.94}+2.40 \times 10^{-2}\left[\left(C_{t}\right)_{\mathrm{avg}}\right]^{0.722} t_{\mathrm{h}}
\end{aligned}
$$

The first term in the equations above represents the cycle-dependent crack growth rate and the other term represents the time-dependent crack growth rate. These equations can be effectively used to predict the service life of high temperature components made of $2 \cdot 25 \mathrm{Cr}-1.0 \mathrm{Mo}$ steel under, both, CCG and CFCG conditions at $594^{\circ} \mathrm{C}\left(1100^{\circ} \mathrm{F}\right)$. An upper and lower scatter band can also be generated for the data in figure 16 for design purposes. This model has been established under the assumption that the crack growth during hold time is only due to creep deformation. Any other time-dependent effects like oxidation at the crack tip have not been incorporated (Grover \& Saxena 1994). Neither have any synergistic effects due to any complicated interactions of the creep and fatigue mechanisms of crack growth during unloading/reloading been incorporated. However, their exclusion in the light of the assumption that the unloading/reloading times are much smaller compared to the hold times seems justified (Grover \& Saxena 1994). If such effects were to be considered, depending 


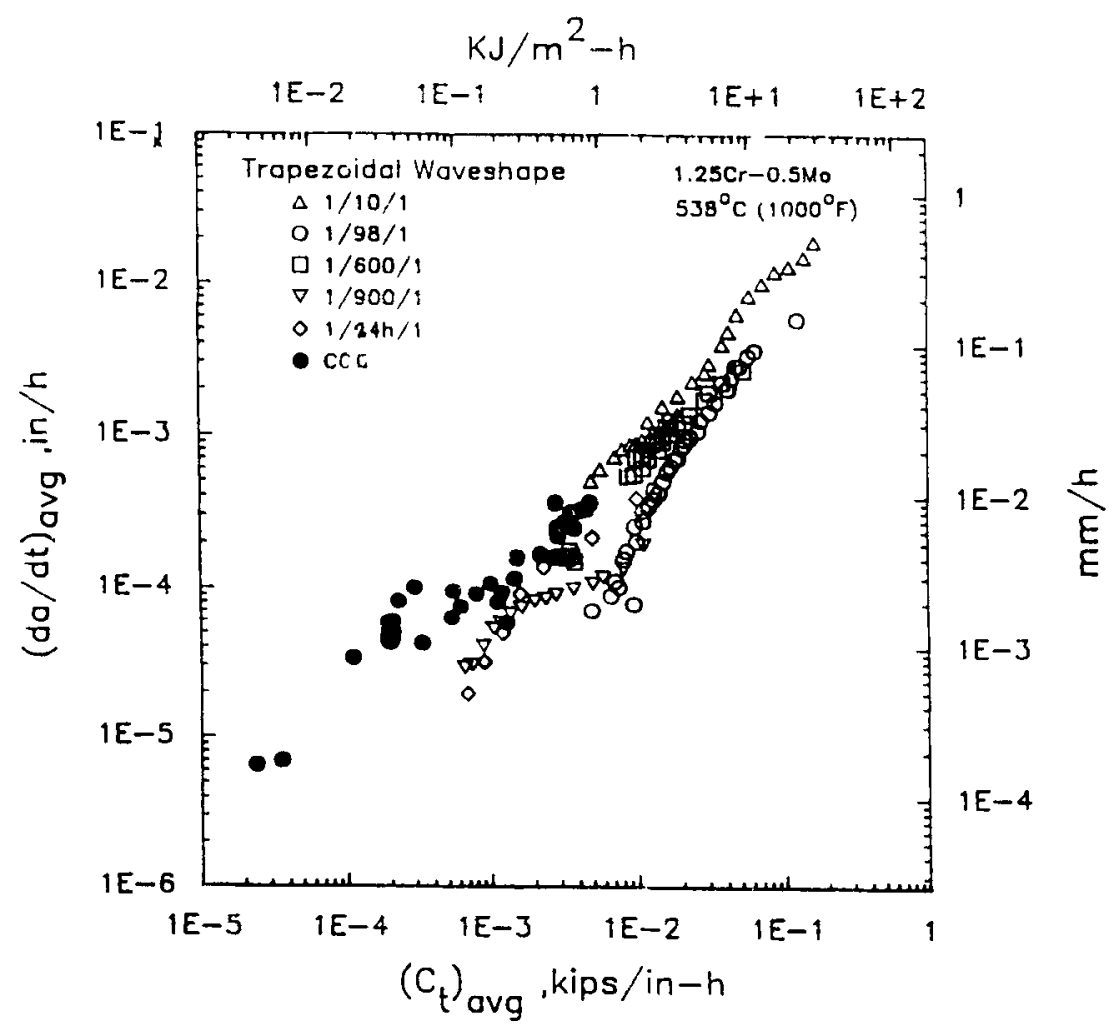

Figure 17. Correlation of crack growth rates for creep and creep-fatigue crack growth data in $1.25 \mathrm{Cr}-0.5 \mathrm{Mo}$ steel (from Yoon et al 1993).

on the material, an equation of the type presented above would be too simplistic in its description of the CFCG behaviour of a material.

\subsection{Calculating CCG and CFCG crack tip parameters in components}

In $\S \S 3 \cdot 1-3 \cdot 4$ the discussion concentrated on obtaining and correlating experimental data with crack tip parameters, $C_{t}$ and $\left(C_{t}\right)_{\text {avg }}$, calculated from experimental quantities measured in the laboratory. Use of directly measured deflection changes to obtain these parameters has advantages discussed by Grover (1993). However, often there is a need to calculate these crack-tip parameters for components in service due to limitations or constraints that might exist in carrying out laboratory tests on the component material. In such an event, the expressions outlined in this section may be used to calculate $C_{t}$ and $\left(C_{t}\right)_{\text {avg }}$ for components, making use of material properties.

$C_{t}$ is related to the rate of expansion of the creep zone for small-scale creep conditions and is expressed as

$$
\left(C_{t}\right)_{\mathrm{SSC}}=2\left(1-v^{2}\right)\left(K^{2} / E W\right)\left(F^{\prime} / F\right) \beta \dot{r}_{c}
$$

where $\beta=1 / 3$ is a factor obtained from finite element analysis, $v$ is the Poisson's ratio and $\dot{r}_{c}$ is the rate of creep zone expansion which is given by (25) and (27) for 
materials deforming by elastic-secondary creep (EL-SC) and elastic-primary creep (EL-PC) respectively. Other terms have been defined earlier,

$$
\dot{r}_{c}=2 x /(n-1) K^{2} t^{-(n-3) /(n-1)}(E A)^{2 /(n-1)} \tilde{r}_{c}(\theta, n) .
$$

where $t$ is time and $\tilde{r}_{c}(\theta, n)$ is a nondimensional constant which varies with the secondary creep constant $n$. $x$ is a scaling factor also dependent on $n$ and is defined below.

$$
x=(1 / 2 \pi)\left[(n+1)^{2} /\left(2 n x_{n}^{n+1}\right)\right]^{(2 ;(n-1))}
$$

where $x_{n}^{n+1} \simeq 0.69$ for $3 \leqslant n \leqslant 13$ (Riedel \& Rice 1980).

For EL-PC materials

$$
\begin{aligned}
\dot{r}_{c}=\frac{K^{2}}{2 \pi} & {\left[\frac{I_{n_{1}} E}{2 \pi\left(1-v^{2}\right)}\right]^{2\left(n_{1}-1\right)}\left[\left(1+n_{1}\right)(1+p) A_{1}\right]^{2 /(1+p)\left(n_{1}-1\right)} } \\
& \times\left[\frac{\tilde{r}_{c}\left(t, n_{1}\right)}{1+p}\right]\left[\frac{2}{n_{1}-1}\right](t)^{\left[2(1+p)\left(n_{1}-1\right)\right]-1}
\end{aligned}
$$

where $I_{n 1}$ is a nondimensional constant dependent on the primary creep constant $n_{1}$. $A_{1}$ and $p$ are also primary creep constants ${ }^{2}$.

For a wide range of creep conditions $C_{t}$ is expressed as

$$
C_{t}=\left(C_{t}\right)_{\mathrm{SSC}}+C^{*}(t)
$$

Expressions for $\left(C_{t}\right)_{\text {avg }}$ can be obtained using (10) and (11) for materials exhibiting complete creep reversal and those that do not, respectively. Corrections can be made for the effects of crack-tip cyclic plasticity (Yoon et al 1992; Grover \& Saxena 1994).

For elastic-cyclic plastic-secondary creep (EL-CPL-SC) materials showing complete creep reversal,

$$
\begin{aligned}
{\left[\left(C_{1}\right)_{\mathrm{avg}}\right]_{\mathrm{SC}}=\frac{2 \alpha \beta \tilde{r}_{c}(\theta, n)}{E}\left(1-v^{2}\right) \frac{\Delta K^{4}}{W} \frac{F^{\prime}}{F}(E A)^{2(n-1)} } \\
\times\left[\frac{\left(t_{h}+t_{p l}\right)^{2 /(n-1)}+\left(t_{p l}\right)^{2 /(n-1)}}{t_{h}}\right]+C_{s}^{*},
\end{aligned}
$$

where $C_{s}^{*}$ is the steady-state part of $C^{*} . t_{p l}$ is the time for the crack-tip creep zone to grow out of the cyclic plastic zone (Yoon et al 1992); thus, it accounts for retardation in the creep zone expansion rate due to the presence of cyclic plasticity. It can be calculated analytically using (30) or (31) (Yoon et al 1992; Grover \& Saxena 1994) for elastic-cyclic plastic-secondary creep (EL-CPL-SC) and elastic-cyclic plastic-primarysecondary creep (EL-CPL-PC-SC) materials. It can also be obtained experimentally (Yoon et al 1992; Grover \& Saxena 1994).

$$
t_{p l}=\frac{1}{E A}\left[\zeta\left(\frac{m-1}{m+1}\right)\left(\frac{1}{2 \sigma_{y s}^{c}}\right)^{2} \frac{1}{\alpha \tilde{r}_{c}\left(90^{\circ}, n\right)}\right]^{(n-1) / 2 .},
$$

\footnotetext{
${ }^{2} n_{1}, A_{1}, p$ are regression constants in the following constitutive equation used to describe the creep behaviour of a material.$$
\dot{\varepsilon}=(\dot{\sigma} / E)+A_{1} \varepsilon^{-p} \sigma^{n_{2}(\dot{1}+p)}+A \sigma^{n} .
$$ 
for EL-CPL-SC materials.

$$
t_{p l}=\frac{1}{(1+p)\left(1+n_{1}\right) A_{1}}\left(\frac{2 \pi\left(1-v^{2}\right)}{I_{n_{1}} E}\left[\xi \frac{2 \pi}{\tilde{r}_{c}\left(\theta, n_{1}\right)}\left(\frac{m-1}{m+1}\right)\left(\frac{1}{2 \sigma_{y}^{c}}\right)^{2}\right]^{\left(n_{1}-1\right) / 2}\right)^{(1+p)},
$$

where $m$ is the plasticity exponent and $\sigma_{y}^{c}$ is the cyclic yield strength of the material. This equation accounts for primary creep effects and is thus suitable for EL-CPL-PC-SC materials.

When primary creep dominates the small-scale creep conditions and then the secondary creep zone grows out from within the primary creep zone, to dominate the steady-state creep condition, $\left(C_{t}\right)_{\mathrm{avg}}$ for EL-CPL-PC-SC materials is expressed as

$$
\begin{aligned}
{\left[\left(C_{i}\right)_{\mathrm{avg}}\right]_{\mathrm{PC}-\mathrm{sC}}=\frac{\beta \tilde{r}_{c}(\theta)}{\pi E}\left(1-v^{2}\right) \frac{(\Delta K)^{4}}{W} \frac{F^{\prime}}{F}\left[\frac{I_{n_{1}} E}{2 \pi\left(1-v^{2}\right)}\right]^{2 /\left(n_{1}-1\right)} } \\
\times\left[\left(1+n_{1}\right)(1+p) A_{1}\right]^{\left.2 /\left(n_{1}-1\right)(1+p)\right]} \\
\times\left[\frac{\left(t_{h}+t_{p l}\right)^{\left.2 /\left(n_{1}-1\right)(1+p)\right]}-\left(t_{p l}\right)^{\left.2 /\left(n_{1}-1\right)(1+p)\right]}}{t_{h}}\right] \\
+C_{s}^{*}\left[1+(1+p)\left(t_{2}\right)^{p /(1+p)}\left(\frac{\left(t_{h}+t_{p l}\right)^{1 /(1+p)}-\left(t_{p l}\right)^{1 /(1+p)}}{t_{h}}\right)\right]
\end{aligned}
$$

where $t_{2}$ is the transition time for extensive secondary creep conditions to develop from small-scale secondary creep zone contained within the primary creep field (Yoon 1990; Saxena 1991).

The crack-growth rate vs crack-tip parameter correlations are then used for life assessment of components as discussed in the next section.

\section{Applications to life prediction}

The primary objective of this section is to briefly describe life prediction procedures, for power plant components, based on the crack-growth concepts discussed earlier. Life assessment of a steam-turbine casing has been discussed as a specific illustration.

\subsection{Remaining life assessment using crack growth models}

The remaining crack growth life assessment methodology includes time-independent fatigue crack growth, time-dependent creep crack growth and creep-fatigue interactions affecting crack growth. These crack growth vs crack tip parameter $\left(\Delta K, C_{t}\right)$ correlations, obtained as discussed in $\$ 3$, are used in the life prediction steps as illustrated in figure 18 (Chell $e t$ al 1993) which is a schematic of the steps involved in using time-dependent fracture mechanics concepts for remaining crack-growth life prediction. Material data, including tensile properties, elastic and creep deformation constants, fracture toughness of the material and the CCG and CFCG constants of the material are required. Stress analysis is conducted on the component based on the operating conditions and the geometry of the cracked component, and the appropriate crack growth model (fatigue/creep/creep-fatigue) is selected for the material. Estimation 


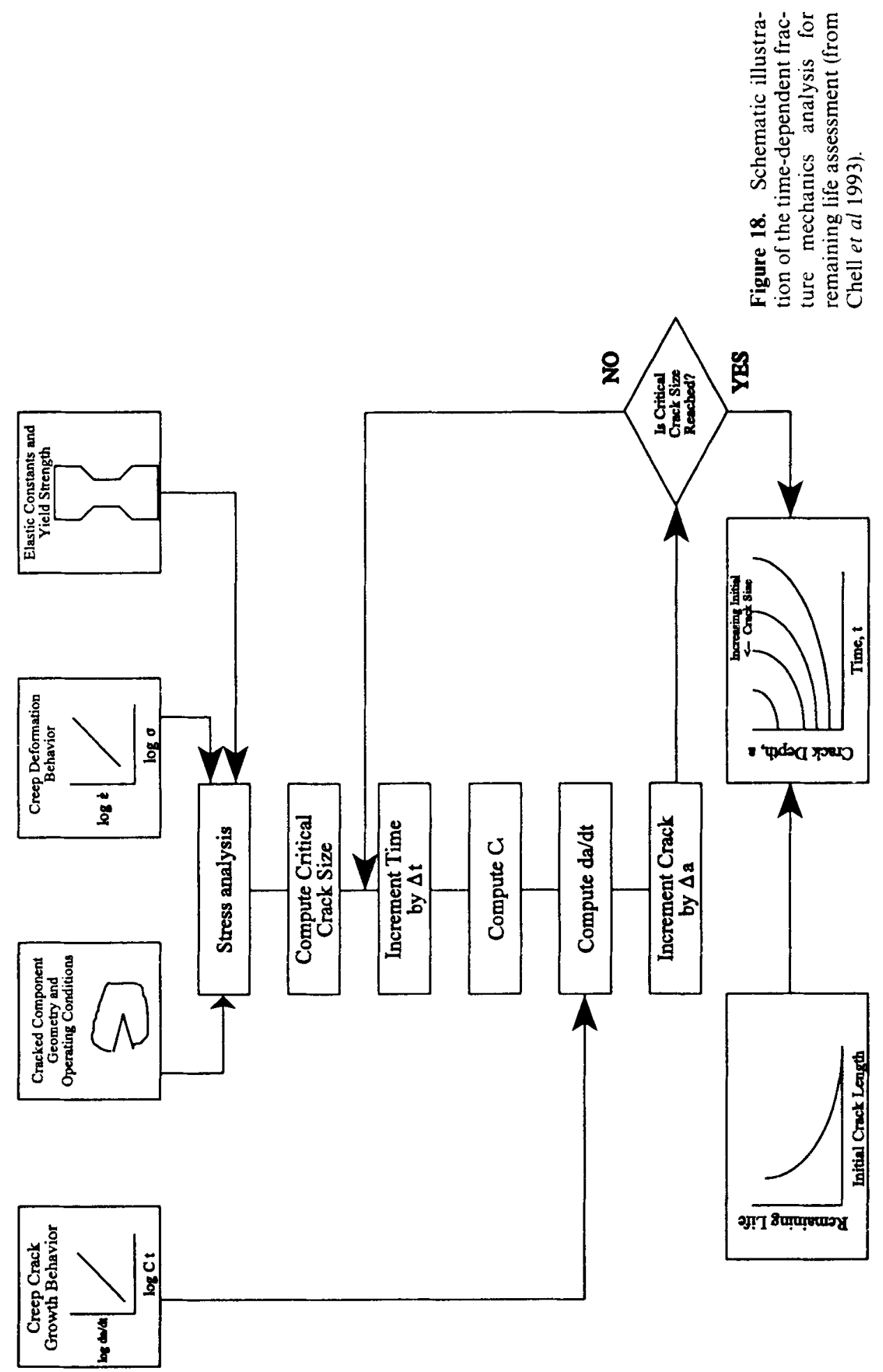


of parameters like $K$ and $C^{*}$ in order to obtain $C_{t}$ is done using expressions available in handbooks (Kumar et al 1981; Tada et al 1986; Zahoor 1991).

Either static or cyclic analysis can be performed for calculating the remaining life. In a static analysis, a component such as a steam pipe or a header is assumed to operate continuously, uninterrupted by start-up and shut-down (Saxena 1993). The life is then estimated as the time for the defect/crack to grow from its initial size, $a_{o}$, to its final size, $a_{f} . a_{o}$ is the crack size at inspection and $a_{f}$ is the critical size at which fracture can occur and is determined from fracture conditions. In a cyclic analysis, explicit account is taken of the start-ups and shut-downs and the life is expressed as the number of such cycles required to grow the crack from $a_{o}$ to $a_{f}$ (Saxena 1993).

Under static conditions, the remaining life, $t_{R}$, is obtained by integrating the CCG rate law (Saxena 1993).

$$
t_{R}=\int_{a_{0}}^{a_{f}} \frac{\mathrm{d} a}{C_{1}\left[C_{t}(a, t)\right]^{q}} .
$$

The creep crack growth rate law (Saxena 1986; Saxena et al 1988) is of the form

$$
\mathrm{d} a / \mathrm{d} t=C_{1}\left[C_{t}(a, t)\right]^{q},
$$

where, $C_{1}$ and $q$ are regression parameters.

Under cyclic loading, the cyclic crack growth rate is first obtained for a given crack size using empirical equations that are in the form of (22) and then a numerical integration is carried out to obtain $t_{R}$ using (Saxena 1993),

$$
t_{R}=\int_{a_{0}}^{a_{f}} \frac{\mathrm{d} a}{(\mathrm{~d} a / \mathrm{d} N)} .
$$

\subsection{Life assessment of turbine casings}

Steam-turbine casings are large castings that encase the stationary and rotating components of the turbine. Their main function is to contain the steam pressure and maintain the alignment of internal components (Viswanathan 1989). These are made from $1.25 \mathrm{Cr}-0.5 \mathrm{Mo}, 2.25 \mathrm{Cr}-1 \mathrm{Mo}$ and $1 \mathrm{Cr}-1 \mathrm{Mo}-0.25 \mathrm{~V}$ steels. Many steam turbines have been used beyond their design lives and, due to economic considerations, the trend has been to use them for cyclic operation. Such factors have made cracking a major concern with regards to the safe operation and operating life of these components. This section aims at briefly providing an insight into the nature of cracking in turbine casings and illustrating the use of remaining crack growth life assessment methodology discussed above.

4.2a Damage mechanisms and failure sites: Cracks in casings are typically located at the steam inlets of HP and IP turbine sections because the local thermal stresses are higher. Figure 19 (Logsdon 1986) shows a schematic of a casing showing inlet steam passages. Cracking in the HP and IP sections is typically found on the interior surfaces of steam chests, valve bodies, bolt holes, seal casings and nozzle chambers (Viswanathan 1989). Figure 20 is a schematic of the crack locations in the nozzle area of a steam-turbine casing (Rasmussen 1986). The primary cause of crack initiation and propagation in turbine casings is fatigue, creep-fatigue and brittle fracture (Logsdon 1986). Thermal stresses are responsible for fatigue and creep-fatigue cracking 


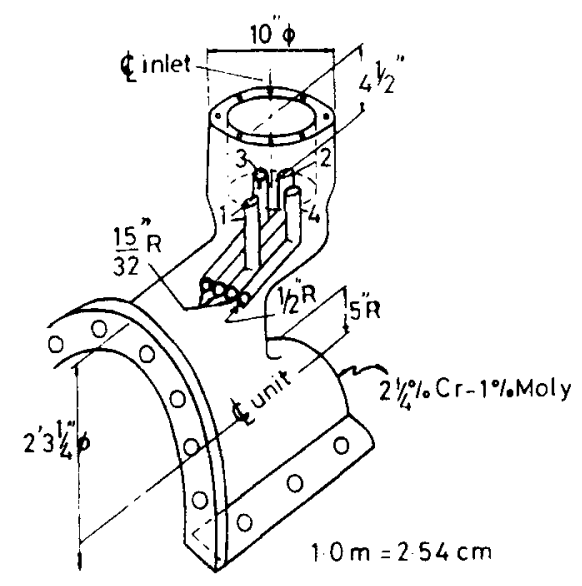

Figure 19. Schematic of steam turbine casing showing inlet steam passages (from Logsdon et al 1986).

while creep contributes to crack growth in regions where temperature exceeds $427^{\circ} \mathrm{C}$ $\left(800^{\circ} \mathrm{F}\right)$ (Saxena 1993). The reader is referred to (Viswanathan 1989; Saxena 1993) for further details on the damage mechanisms and failure sites in turbine casings.

4.2b Remaining life estimation: Casings are made of relatively ductile materials and have large section areas which are not highly stressed. Thus, remaining-life assessments are generally based on crack-growth considerations rather than crack-initiation considerations, which are more useful at the design stage (Viswanathan 1989). The basic information needed for remaining life estimation of turbine casings is given below (Saxena 1993).

* Operating history, including the number and type of starts (cold/warm/hot) per year. The thermal ramp rates during heating and cooling, the amount of prewarming and metal temperature at each stage in order to determine thermal stresses.

* Material properties like monotonic and cyclic stress-strain behaviour, creep stress relaxation rates, fracture toughness, and, the fatigue and creep-fatigue crack initiation behaviour as a function of temperature. Further, this information is also needed for weldments, if they are involved.

Determination of various material properties is described by Saxena et al (1986). Using the above information, remaining life estimation can be performed following the steps listed below.

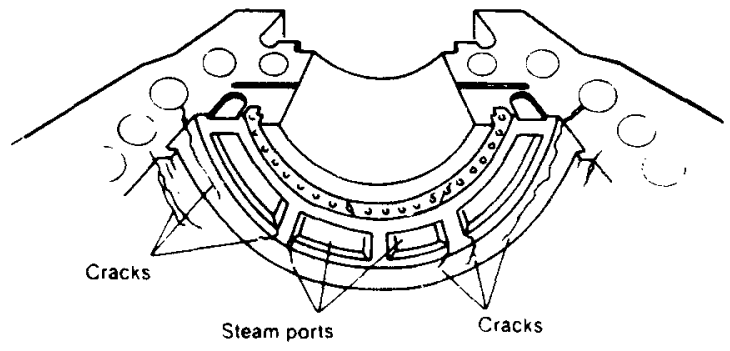

Cracks at various locations are indicated by wiggly fines.
Figure 20. Crack locations in first-stage nozzle area of a steam-turbine casing (from Rasmussen 1986). 


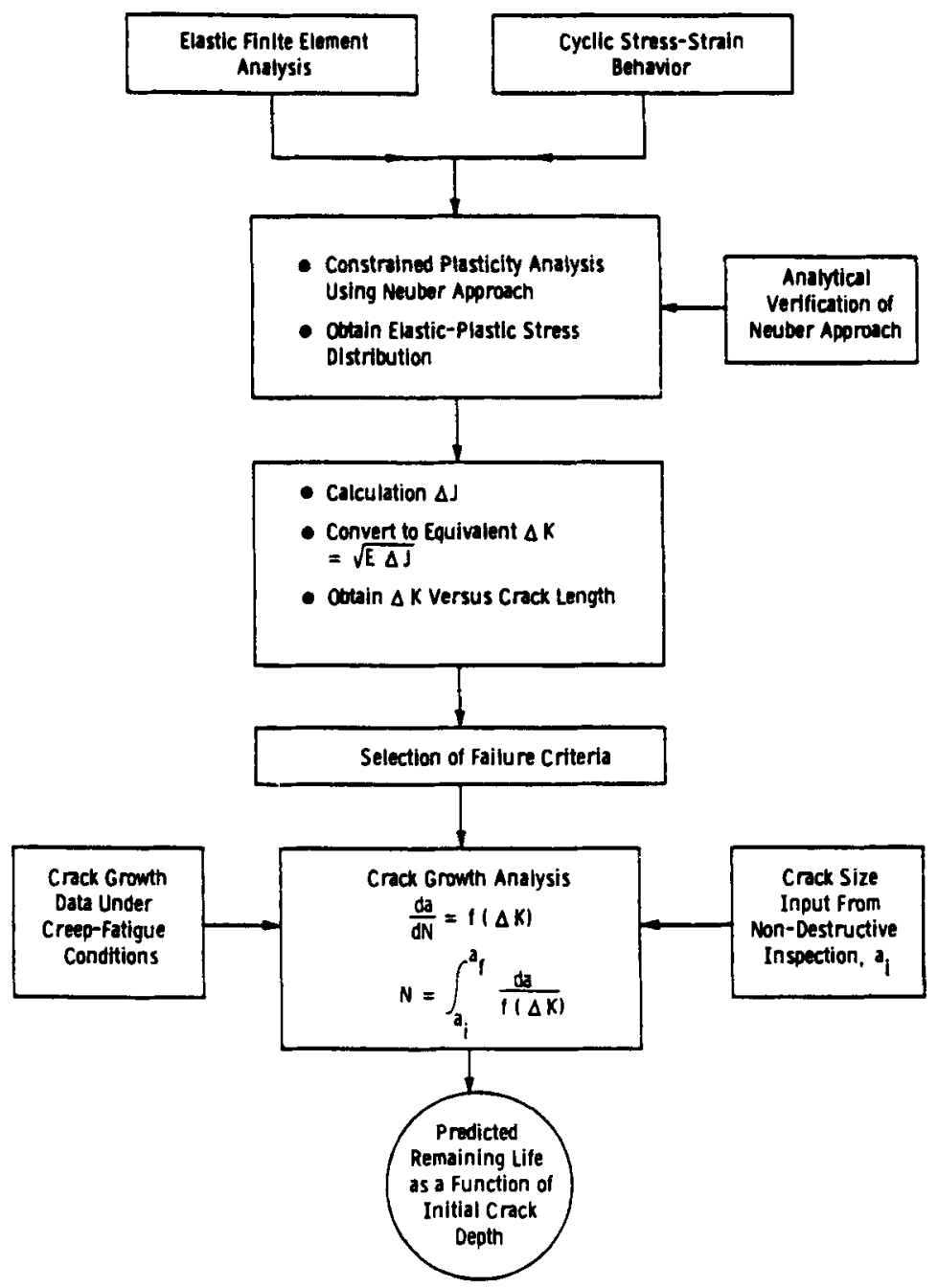

Figure 21. Schematic of the methodology for remaining life prediction (from Saxena et al 1986).

(1) Determine the transient cyclic stresses for the turbine casing for the various operating histories by conducting a finite element analysis for the specific casing design. The first step in this analysis is the generation of transient temperature distribution using heat transfer analysis. The temperatures thus obtained are input into the stress analysis portion of the program along with the pressure and external loads.

(2) The stress-strain and time histories at critical locations are then used to predict the fatigue and creep-fatigue crack initiation and propagation behaviour using the models described earlier. The total remaining life is the sum of the crack initiation and the crack propagation lives. However, if cracks have already initiated, only crack propagation life must be determined. 


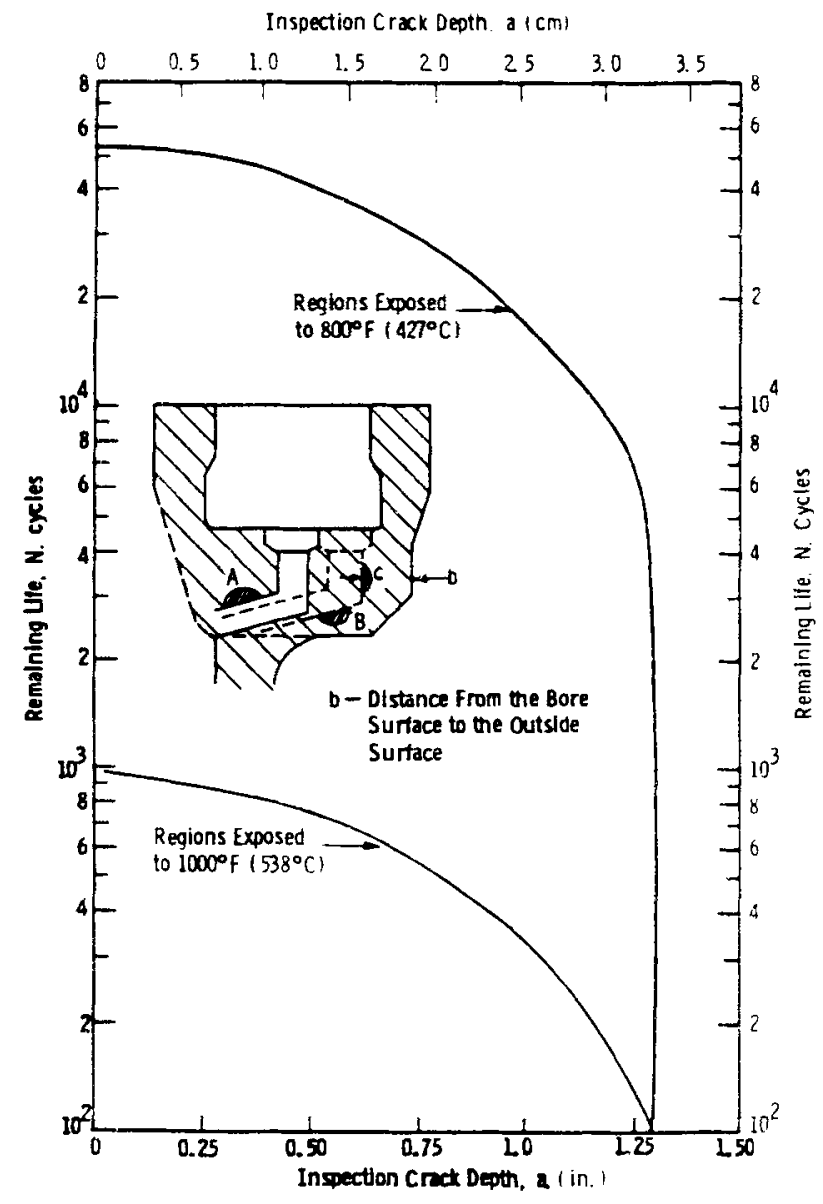

Figure 22. Remaining life as a function of crack depth for cracks in a steam turbine casing (from Saxena et al 1986).

Figure 21 (Saxena et al 1986) is a schematic of the various steps involved in conducting fracture mechanics analysis for remaining life prediction of a cracked turbine casing. Further, figure 22(Saxena et al 1966) shows the results of calculation of remaining life as a function of initial crack size for a ship's service turbine generator casing (SSTG casing).

\section{Special considerations for high-temperature crack growth in weldments}

Most of the problems encountered in heavy-section piping occur at welded joints. Thus, it is desirable to focus damage-assessment techniques on these areas rather than on the base metal. However, many problems that are unique to weldments make both stress analysis and material characterization extremely challenging (Viswanathan 1989). Some of these problems are discussed below.

(1) The weldment can be considered a composite material consisting of the base metal, three or more heat-affected zones (HAZ) and the weld metal. Thus, there is an unpredictability in the modeling of its mechanical behaviour. 


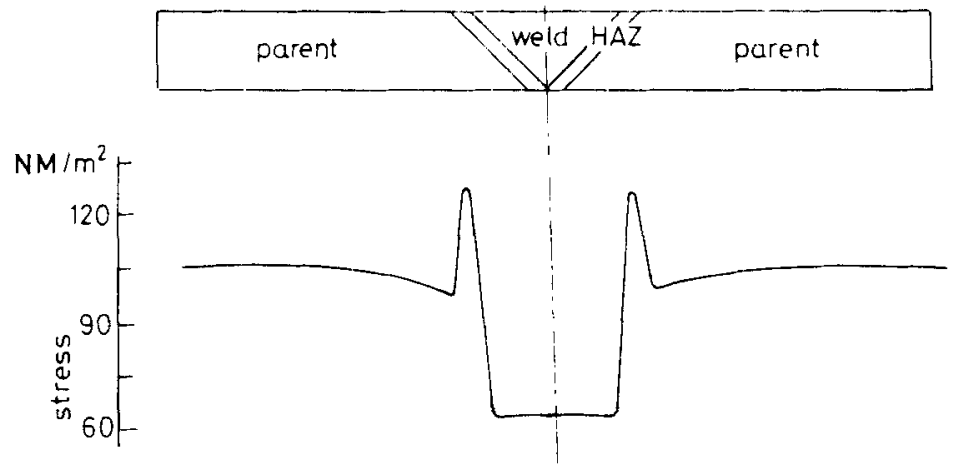

Figure 23. Distribution of steady-state hoop stress across a girth weld in a steam pipe. The initially uniform elastic stress distribution redistributes such that weak weld metal off-loads stress to the stronger parent metal (from Viswanathan et al 1982).

(2) Collection of impurities and inclusions occurs at the fusion line between the weld and the HAZ because it is the last region to solidify. This creates complications in stress analysis.

(3) Uniaxial creep rupture data for a material cannot be used to predict the rupture properties of the weld because multiaxial stress state exists at a weld. This is due to the complex geometry and influence of complex loading. Consequently, the creep resistances of the base metal, the weld metal and the HAZ are quite different and cause the redistribution of initial elastic stresses in complex ways. These distributions can be different for girth welds and for seam welds. In girth welds the pressure stresses in the axial and hoop directions peak at the most creep-resistant (strongest) location, i.e. the HAZ, and are lowest at the weld metal, which is the least creep-resistant location (Cane 1982). This is shown in figure 23 (Viswanathan et al 1982). However, in seam welds, the peak stresses after stress redistribution occur in the weld metal (weakest location) and the lowest stresses are encountered in the HAZ (Wells 1987).

(4) A good material-property database does not exist for weldments. The limited amount of available data pertains only to pure base metal, weld metal, or just to the HAZ material. Thus, prediction of crack growth in weldments is not a trivial task. Generation of such data in the laboratory is not easy either. Thus, in the absence of a reliable database, the convenient practice has been to assume the weld to be always weaker than the base metal and then using base metal properties to model the weld behaviour by applying arbitrary safety factors.

(5) Welds also serve as sites for fabrication defects which can act as stress raisers and preferred sites for cavity growth and crack initiation. The presence of impurities like sulphur further worsens the situation.

As mentioned above, both the crack growth database and the analytical procedures are inadequate. Significant developments are thus needed in addressing cracking problems in elevated temperature weldments. 


\section{References}

Anderson T L 1991 Fracture mechanics Fundamentals and applications (Boca Raton. FL: CRC Press)

Adefris $\mathrm{N} 1993$ Creep-fatigue crack growth behatiour of $1^{\circ}{ }_{n} G 1 \cdot 1 \mathrm{Mo}-1 / 4_{\%}^{\circ} \mathrm{V}$ rotor steel. Doctoral thesis, School of Materials Science and Engineering, Georgia Institute of Technology. Atlanta, GA

Altekar V A 1980 Power crisis and the metallurgical engineers. N P Gandhi Memorial Lecture, Indian Institute of Metals, Baroda

ASTM 1991 Standard test method for measurements of fatigue crack growth rates: ASTM Standard E 647-91. ASTM Book of Standards, Vol. 03.01; pp. 654-681

ASTM 1992 Standard test method for measurement of creep crack growth rates in metals: ASTM Standard E 1457.92. ASTM Book of Standards, vol. 03.01, pp. 1031 1043

Bassani J L, Hawk D E, Saxena A 1989 Evaluation of the $C_{t}$-parameter for characterizing creep crack growth rate in the transient regime. In Nonlinear fracture mechanics: Volume I Time dependent fracture (eds) A Saxena et al ASTM STP 995, pp. 7-26

Bassani J L, McClintok F A 1981 Creep relaxation of stress around a crack tip. In Int. J. Solids Struct. 7: 479-492

Cane B J 1982 In Proceedings of International Conference on Welding Technology for Energy Applications ORNL Conference 820554, Gatlinburg, TN, pp. 623.639

Cheil G G. Hudak S J, Swaminathan V P, Leung C P. Saxena A 1993 A high-temperature fitness-for service assessnient methodology for petrochemical processing vessels. (ASME) (in press)

Dooley R B. Viswanathan R (eds) 1987 Life extension and assessment of fossil power plants. (Palo Alto, CA: Electric Power Research Institute) EPRI CS 5208

Ehlers R, Riedel H 1981 A finite element analysis of creep deformation in a specimen containing a macroscopic crack. In Advances in fracture research: Proceedings of the Fifth International Conference on Fracture (New York: Pergamon) ICF-5: 691 1 698

Goldman N L. Hutchinson J W 1975 Fully plastic crack problems: The center-cracked strip under plane strain. Int. J. Solids Struct. 11: 575 - 591

Grover P S 1993 An accelerated test methodology for creep-fatigue crack growth testing. $M S$ thesis. School of Materials Science and Engineering. Georgia Institute of Technology, Atlanta, GA

Grover P S, Saxena A 1994a Developments in creep-fatigue crack growth testing and data analysis. Paper to be presented at the Tenth European Conference on Fracture. Berlin, Germany

Grover P S, Saxena A 1994b Characterization of creep-fatigue crack growth behavior in $2 \cdot 25 \mathrm{Cr}-1.0 \mathrm{Mo}$ steel using $\left(C_{t}\right)_{\text {avg }}$. Int. J. Fract. (submitted)

Harrison C B. Sandor G N 1971 Eng. Fract. Mech. 3: 403- 420

Jaffee R I 1979 Metallurgical problems and opportunities in coal fired steam power plants. Metall. Trans. A10: 139-165

Kumar V, German M D, Shih C F 1981 An engineering approach to elastic-plastic analysis. Technical Report EPRI NP-1931, Electric Power Research Institute

Kuwabara K, Nitta K. Kitamura T, Ogala T 1988 Effect of small-scale creep on crack initiation and propagation under cyclic loading. In Basic questions in fatigue (eds) R P Wei, R P Gangloff. ASTM STP 924, vol. 2. p. 41

Landes J D, Begley J A 1976 A fracture mechanics approach to creep crack growth. In Mechanics of track growth ASTM STP 590, pp. 128-148

Lee D R 1987 personal communication

Leung C P, McDowell D I., Saxena A 1988 Consideration of primary creep at stationary crack tips: Implications for the $C_{1}$-parameter. Int. J. Fracture 36: 275-289

Logsdon W A, Liaw P K, Saxena A, Hulina V E 1986 Residual life prediction and retirement for cause criteria for SSTG upper casings I - Mechanical and fracture mechanics materials properties development. Eng. Fract. Mech. 25: 259-288

McDowell D L, Leung C P 1988 Estimation of the $C_{t}$-parameter for primary creep. Technical Report E-18-621, GA Technologies, Palo Alto, CA 
Nikbin K M, Webster G A, Turner C E 1976 Relevance of nonlinear fracture mechanics to creep cracking. In Cracks and fracture ASTM STP 601, pp. 47-62

Ohji K 1986 Fracture mechanics approach to creep-fatigue crack growth. In Role of fracture mechanics in modern technology (Fukuoka, Japan) (eds) G C Sih. H Nisitani, T Ishihara (Elsevier Science)

Ohji K, Ogura K, Kubo S 1979 Stress-strain field and modified $J$-integral in the vicinity of a crack tip under transient creep conditions. Jpn. Soc. Mech. Eng. 790 (13): 18-20 (in Japanese)

Ohtani R, Kitamura T, Nitta A, Kuwabara K 1989 High-temperature low-cycle fatigue crack propagation and life laws of smooth specimens derived from the crack propagation laws (eds) H Solomon, G Halford, L Kaisand, B Leis; ASTM STP 942, pp. 1163-1180

Ohtani R, Kitamura T, Yamada K 1981 A nonlinear fracture mechanics approach to crack propagation in the creep-fatigue interaction range. In Fracture mechanics of tough and ductile materials and its application to energy related structures (eds) H Liu, T Kumio, V Weiss (Martinus Nijhoff) pp. 263-270

Rasmussen D M 1986 Steam turbine case repairs to extend operating life. In Workshop Proceedings: Life assessment and repair of steam turbine casings (ed.) $\mathrm{R}$ Viswanathan (Palo Alto, CA: Electric Power Research Institute) CS 4676 SR, pp 6.1 - 7.1

Rice J R 1968 A path independent integral and the approximate analysis of strain concentration by notches and cracks. J. Appl. Mech. 35: 379-386

Riedel H 1983 Crack tip stress fields and crack growth under creep-fatigue conditions. In ElasticPlastic Fracture: Second Symposium, Volume I - Inelastic Crack Analysis ASTM STP 803, pp 505-520

Riedel H 1987 Fracture at high temperature (Berlin: Springer-Verlag)

Riedel H, Detampel V 1987 Creep crack growth in ductile, creep resistant steels. Int. J. Fracture 33: $239-262$

Riedel H, Rice J R 1980 Tensile cracks in creeping solids. In Fracture mechanics: Twelfth Conference ASTM STP 700, pp. 112.130

Saxena A 1980 Evaluation of $C^{*}$ for the characterization of creep crack growth behaviour in 304 SS. In Fracture mechanics: Twelfth Conference ASTM STP 700, pp. 131-151

Saxena A 1986 Creep crack growth under non-steady-state conditions. In Fracture mechanics (eds) J H Underwood et al ASTM STP 905, 17: 185-201

Saxena A 1988 Limits of linear elastic fracture mechanics in characterization of high-temperature fatigue crack growth. In Basic questions in fatigue (eds) R P Wei. R P Gangloff, ASTM STP 924, 2: 27-40

Saxena A 1989a Mechanics and mechanisms of creep crack growth. In Fracture mechanics: Microstructure and micromechanisms (eds) S Nair et al (Metals Park, OH: ASM International) Chap. 10, pp. 283-334

Saxena A 1989b Recent advances in elevated temperature crack growth and models for life prediction. In Advances in Fracture Research: Proceedings of the Seventh International Conference on fracture (eds) K Salama et al (New York: Pergamon) ICF-7: 1675-1687

Saxena A 1991 Creep crack growth in high temperature ductile materials, Enyineering fracture mechanics 40: $721-736$

Saxena A 1993 Fracture mechanics approach for characterizing creep-fatigue crack growth (Review Paper). Jpn Soc. Mech. Eng. Int. J. A36: 1-20

Saxena A 1993 Life assessment methods and codes (Palo Alto, CA: Electric Power Research Institute)

Saxena A, Bassani J L 1984 Time dependent fatigue crack growth behavior at elevated temperature. In Fracture: Interactions of microstructure, mechanics and mechanics ASTM STP 743, (Warrendale, PA: The Metallurgical Society of AIME)

Saxena A, Ernst H A, Landes J D 1983 Creep crack growth behavior in 316 stainless steel at 594 C. Int. J. Fracture 23: 245-257

Saxena A, Gieseke B 1990 Transients in elevated-temperature crack growth. In International Seminar on High Temperature Fracture Mechanics and Mechanics, EGF-6 (Dourdan, France: Elsevier) 3: 19-36

Saxena A, Han J, Banerji K 1988 Creep crack growth behavior in power plant boiler and steam pipe steels. J. Pressure Vessel Technol. 110:137-146 
Saxena A, Liaw P K, L ogsdon W A, Hulina V E 1986 Residual life prediction and retirement for cause criteria for SSTG upper casting II - fracture mechanics analysis. Eng. Fract. Mech. 25: 289-303

Shih C F 1983 Tables of Hutchinson-Rice--Rosengren singular field quantities. Technical Report MRL E-147, Brown University, Providence. RI

Tada H, Paris P, Irwin G R 1986 Srress analysis of cracks handbook (St. Louis. MO: Del Research Col

Viswanathan $\mathbf{R} 1989$ Damage mechanisms and life assessment of high-temperature components (Metals Park, OH: ASM International)

Viswanathan R, Dooley R B 1986 Creep life assessment techniques for fossil plant boiler pressure parts. Proceedings of International Conference on Creep, JSME-IME-ASTMASME, Tokyo, pp. 349-359

Viswanathan R, Messing A, Narayanan T V 1982 Improved life assessment techniques for boiler superheater/reheater pressure parts. EPRI Project Report RP 2253-13, Electric Power Research Institute, Palo Alto, CA

Wells C H 1987 On the life prediction of longitudinal seam welds. In Life extension and assessment of fossil power plants (eds) R B Dooley, R Viswanathan (Palo Alto, CA: Electric Power Research Institute) CS 5208

Yoon K B 1990 Characterization of creep-fatigue crack growth behaviour using the G-parameter Doctoral thesis. School of Mechanical Engineering. Georgia Institute of Technology, Atlanta. GA

Yoon K B. Saxena A, Liaw P K 1993 Characterization of creep fatigue crack growth behavior under trapezoidal waveshape using $C_{1}$-parameter. In Int. J. Fracture 59: 95-114

Yoon K B. Saxena A, McDowell D L 1992 Influence of crack tip cyclic plasticity on creep-fatigue crack growth. In Fracture Mechanics: Twenty Second Symposium (eds) H A Ernst. A Saxena, D L McDowell ASTM STP 1131, pp. 367-392

Zahoor A 1991 Ductile fracture handbood (Palo Alto. CA: Eloctric Power Research Institute) EPRI 1757-69 